\title{
Direct-interception feeding by marine zooflagellates: the importance of surface and hydrodynamic forces*
}

\author{
B. C. Monger, M. R. Landry \\ Department of Oceanography, University of Hawaii at Manoa, 1000 Pope Road, Honolulu, Hawaii 96822, USA
}

\begin{abstract}
We present a theory of direct-interception feeding by marine zooflagellates based upon fundamental principles of hydrodynamics and physical chemistry. Analysis shows that in the absence of confounding behaviors the balance between fluid drag and a complex set of surface-forces uniquely determines prey trajectories about zooflagellate grazers and consequently, clearance rate (volume cleared flag. ${ }^{-1} \mathrm{~h}^{-1}$ ) and specific clearance rate (volume cleared [volume flag.] $]^{-1} \mathrm{~h}^{-1}$ ). As a first approximation to this general 'Force-Balance' approach, we utilize a model taken from the filtration literature (Spielman \& Goren 1970 (Environ. Sci., Tech. 4: 135-140]) in which wall-corrected fluid drag is balanced with the London-van der Waals force $\left(F_{\text {London }}\right)$. Using literature estimates of $F_{\text {London, }}$ and $a$ standard grazer swimming speed $\left(\mathrm{U}_{\mathrm{g}}\right)$ of $200 \mu \mathrm{m} \mathrm{s} \mathrm{s}^{-1}$, clearance rates $\left(\mathrm{Clr}_{\mathrm{k}}\right)$ and specific clearance rates $\left(\mathrm{SpClr}_{\mathrm{FB}}\right)$ are predicted to range respectively from 0.13 to $1.8 \mathrm{nl} \mathrm{flag}^{-1} \mathrm{~h}^{-1}$ and from 0.09 to $7.6 \times 10^{4} \mathrm{~h}^{-1}$ for grazer $\left(R_{g}\right)$ and prey $\left(R_{p}\right)$ radii typical of zooflagellate-picoplankton interactions. Analysis shows that $\mathrm{Clr} F \mathrm{~F}$ is roughly proportional to $\mathrm{R}_{\mathrm{p}}^{0.8}$ which strongly contrasts with the $\mathrm{R}_{\mathrm{p}}^{2.0}$ proportionality predicted by a model based on geometric considerations (Fenchel 1982a [Mar. Ecol. Prog. Ser 8: 211-223], 1984 [in: 'Flows of energy and materials in marine ecosystems', Plenum Press]). For given zooflagellate and prey size, $\mathrm{Cl}_{\mathrm{FB}}$ can be up to 10 times greater than Geometric model predictions with the greatest disparity between models occurring for relatively large grazers feeding on small prey. $\mathrm{Clr}_{\mathrm{FB}}$ is generally within a factor of 2 of empirical values in the literature, but in some instances underpredicts by an order of magnitude. The remaining discrepancies may be explained by uncertainties in grazer size, swimming speeds and London-van der Waals force. Attempts to incorporate nonspherical shapes, flagellar hydrodynamics, and hydrophobic and steric forces remain viable areas for fine-tuning the model's predictive capabilities
\end{abstract}

\section{INTRODUCTION}

The importance of bacterioplankton in the cycling of carbon and major nutrients in the ocean has been widely recognized over the past decade (Azam et al. 1983, Hobbie \& Williams 1984, Ducklow et al. 1986), and with that recognition has come an interest in the organisms that utilize and control bacteria. Small ciliates and collared flagellates may contribute significantly to grazing on bacterioplankton in coastal waters (e.g. Fenchel 1982b, Sherr \& Sherr 1987). In general however, and particularly in the open ocean, the dominant consumers of bacteria appear to be small zooflagellates lacking well-defined filter-feeding struc-

\footnotetext{
- Contribution No. 2297 from the School of Ocean and Earth Sciences and Technology
}

tures. As described by Fenchel (1984), these organisms feed by the mechanism of 'direct-interception', meaning that their swimming activities bring them into random contact with picoplankton-sized prey. At least to a first approximation, direct-interception feeding occurs without the structural complexity, hence inter-taxonomic variability, of filter-feeders or the obvious behavioral complications of higher organisms, including many ciliated protozoa. Consequently, direct-interception feeding by zooflagellates is both a tractable and ecologically meaningful model system for developing and testing our understanding of the physical forces governing trophic interactions of microorganisms in the oceans.

Fenchel (1982a, 1984) previously analyzed the mechanism of direct-interception feeding in the context of Spielman's (1977) 'Geometric' model for particle 
capture by spherical collectors. As the name implies, this model is based strictly on geometric considerations and, as will be shown, represents a physically unrealistic approximation of the actual capture process. Fenchel $(1982 a, 1984)$ recognized the simplistic nature of the model and advanced it only to illustrate order-ofmagnitude effects and to compare its implication relative to other protozoan feeding strategies. To our knowledge, no critical examination of direct-interception feeding by marine zooflagellates has been presented in the literature (but see LaBarbera 1984).

In the present paper, we describe the physical basis of direct-interception feeding to clarify the complex nature of this process and to set a general framework for future study. Within this context we develop a Force-Balance modeling approach and present a model of first order approximation, borrowed from the filtration literature (Spielman \& Goren 1970). Predictions of clearance-rate and associated size dependency derived from this model are presented. With a few exceptions, the model yields estimates of clearance rates that are generally of comparable magnitude with observed rates obtained from the literature. In addition, the model predicts clearance rates that are generally higher, and at times an order of magnitude higher, than predictions of the Geometric model. Moreover, the model markedly alters predicted size-dependencies based on geometric considerations alone.

None of the concepts we present in this paper are in themselves new, indeed some have been around for more than $50 \mathrm{yr}$ ! What we have attempted to do in this paper is combine the varied concepts from the colloid, physical chemistry and filtration literature into a reasonably comprehensive description of the capture process. By expressing the capture process, as we do here, in terms of a sum of individual force components, each component may be studied separately under controlled experimental conditions. It then becomes possible to develop future grazing models in a logical stepwise manner.

\section{THEORETICAL CONSIDERATIONS}

\section{Langrangian description of the direct-interception process}

The direct-interception process may be modelled in either an Eulerian or Langrangian reference frame (Adamczyk et al. 1983). We have chosen a Langrangian reference frame because it offers an intuitively satisfying representation of the capture process and because it is consistent with previous descriptions (Spielman 1977. Fenchel 1982a, 1984). We assume that the flagellate grazer swims through the fluid at constant velocity $\left(\mathrm{U}_{\mathrm{g}}\right)$ and adopt a reference frame which moves with the grazer such that the fluid appears to flow past it with a uniform free-stream velocity $-U_{g}$. Prey (picoplankton) are carried near and subsequently intercepted at the grazer surface by the combined effects of the 'moving fluid' (hydrodynamic forces) and any externally applied forces

By adopting this conceptualization, Brownian motion of the prey and fluid turbulence are implicitly ignored. However, based on the following arguments these 2 processes are not expected to have a significant effect on interception. It has been shown that the interception rate determined by a trajectory analysis which incorporates Brownian motion is equivalent to summing the interception rate due to Brownian motion alone with the rate determined by a trajectory analysis without Brownian motion (Spielman 1977). Fenchel (1984) has shown that 'diffusion feeding' via Brownian motion of bacteria is 2 to 3 orders of magnitude lower than feeding by direct-interception alone. Neglect of Brownian motion, therefore, is valid. Lazier \& Mann (1989) have shown that for scales less than a few millimeters, turbulent motions in the ocean can be approximated as local regions of linear velocity shear that vary in direction and magnitude as a function of space and time. Interception resulting from a linear velocity shear has been determined empirically by Purcell (1978) and is discussed by Lazier \& Mann (1989) in terms of 'turbulent diffusion'. By assuming a velocity shear of $0.16 \mathrm{~s}^{-1}$ (Lazier \& Mann 1989), a grazer diameter of $10 \mu \mathrm{m}, \mathrm{a}$ Brownian diffusion coefficient of $5 \times 10^{-9} \mathrm{~cm}^{2} \mathrm{~s}^{-1}$ (Fenchel 1984), and the empirical data of Purcell (1978), interception due to turbulent motions is expected to be roughly equal to the rate of interception by Brownian motion alone. Therefore, the effects of turbulent motions on prey capture are probably negligible.

By determining the motion of prey particles from equations expressing the net hydrodynamic and external forces, a set of prey trajectories near a grazer can be determined. From this set of trajectories, a critical trajectory is identified as that which carries a prey closest to the grazer surface without being captured. Any prey with trajectories residing within the critical trajectory will contact the surface of the collector. Accordingly, ingestion and clearance rate are, respectively, the particle and volume flux through the cross-sectional area of the critical trajectory found in the undisturbed flow, far upstream of the collector (see Fig. 1). Consequently, with accurate descriptions of the hydrodynamic and external forces acting on prey, grazer clearance rates can be predicted. The fundamentals of these 2 classes of forces are described below. It is shown that fluid drag is directly related to the externally applied forces by the required balance of forces. The motion of a particle, in turn, can be related to the fluid drag using Stokes' momentum equations. The application of 


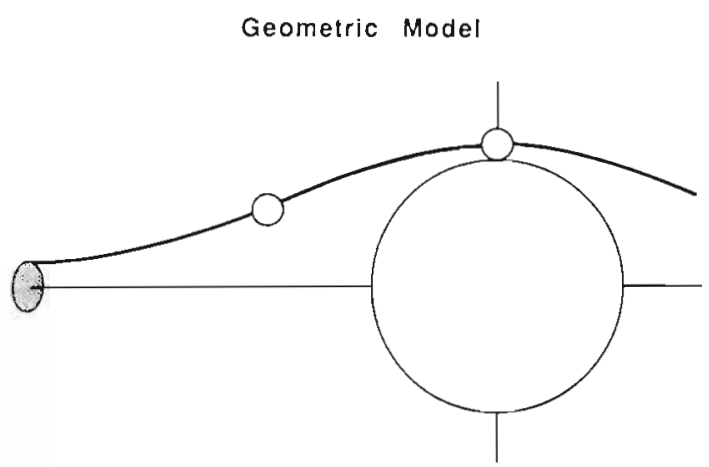

Force Balance Model

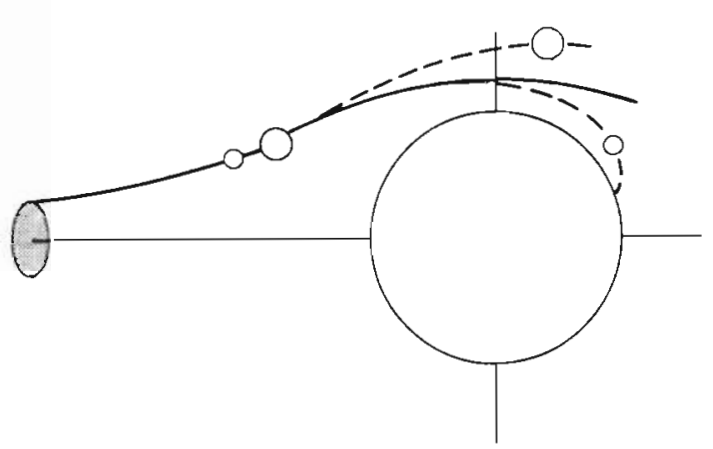

Fig. 1. Qualitative comparison of prey trajectories for the Geometric and Force-Balance models. Solid lines depict fluid streamlines, dashed lines are possible prey trajectories. In the Geometric model, prey follow streamlines. In the ForceBalance model, prey trajectories may deviate from fluid streamlines depending on the relative strengths of attractive surface-forces and a repulsive hydrodynamic interaction force. Decreasing prey size shifts these forces in favor of attractive surface-forces and prey are pulled in from their original streamline. For larger prey, repulsive hydrodynamic interaction forces are favored and prey are pushed away from their original streamline

appropriate boundary conditions to Stokes' equations is shown to be important for accurate solutions. External forces which may be potentially important to the capture process are described in the final section.

\section{Solid-body motion under an applied force at low Reynolds number}

Fluid motions at velocity and size scales typical of zooflagellate-picoplankton interactions are in a low Reynolds Number ( $\mathrm{Re}$ ) regime; thus, the inertial force of the fluid is negligible relative to all other forces. Under such conditions, the resultant of the viscous and pressure gradient forces within the fluid, together with any externally applied body forces on the fluid, is zero to order Re. An immersed solid body experiencing an applied external force $\left(F_{\text {ext }}\right)$ will impart a body-force of the same magnitude on the surrounding fluid. The body-force on the fluid, in turn, is balanced by viscous and pressure gradient forces within the fluid that ultimately produce a retarding fluid drag on the solid body. The overall result is zero net force and torque on any solid-body moving through a fluid at low Re under an applied external force (i.e. $F_{d r a g}+F_{\text {ext }}=0$ ). Because fluid drag is a unique function of the rate of solid-body translation and rotation through the fluid, for any given external force acting on a solid body, the resulting motion needed to produce the appropriate balancing fluid drag can be determined.

The relationship between low Re motion of a solid body through a fluid and the resulting fluid drag is obtained from the solution to Stokes' momentum equations. For a spherical solid body immersed in a fluid of infinite extent, the drag force is given by;

$$
F_{\text {drag }}=-6 \pi \mu R_{\mathrm{s}}\left(\mathrm{U}_{\mathrm{s}}-\mathrm{U}_{\mathrm{fl}}\right)
$$

where $\left(U_{\mathrm{s}}-U_{\mathrm{fl}}\right)=$ velocity of the sphere relative to the moving fluid; $\mu=$ dynamic viscosity; $R_{s}=$ radius of the sphere. This is the familiar Stokes drag equation. By balancing the fluid drag force with $F_{\text {ext }}$, we obtain from Eq. (1);

$$
\left(U_{s}-U_{f l}\right)=F_{e x t} /\left(6 \pi \mu R_{s}\right),
$$

which expresses the relationship between the relative motion of a sphere through a fluid under an applied external force. Note that for the special case $F_{\text {ext }}=0$, we find $U_{\mathrm{s}}=\mathrm{U}_{\mathrm{fl}}$, and the sphere follows the fluid streamlines exactly.

Eq. (1) is strictly valid only for a sphere immersed in an unbounded fluid. The presence of a nearby solid boundary will significantly alter the fluid drag experienced by a moving sphere. The influence of a nearby solid boundary on the fluid drag force manifests itself in 2 ways. First, the solid boundary sets up a new far-field boundary condition for the fluid flow around the sphere. Instead of the fluid velocity going to its freestream value far from the sphere in all directions, it must go to zero at the nearby solid boundary due to the physical requirement of no fluid-slip. Second, the motion of the sphere very near the solid boundary exerts a force on the boundary through the intervening fluid. This, in turn, produces a retarding force on the sphere as it moves relative to the boundary. The expression for the drag on a spherical particle moving through a fluid near a solid boundary may be expressed in the form

$$
F^{\prime} \text { drag }=-6 \pi \mu R_{s}\left(f_{L} U_{s}-f_{2} U_{f 1}\right)
$$

where $F^{\prime}{ }_{\text {drag }}=$ 'wall-corrected' fluid drag force; $\mathrm{f}_{1}$ and $\mathrm{f}_{2}$ $=$ functions of $h / R_{p}$, where $h$ is the gap distance between the sphere and the solid boundary. The functions $f_{1}$ and $f_{2}$ are vector quantities derived from exact solutions to Stokes' momentum equations for steady 
flow using appropriate boundary conditions. The functions $\mathrm{f}_{1}$ and $\mathrm{f}_{2}$ are corrections to $\mathrm{F}_{\text {drag }}$ arising, respectively, from the sphere-solid boundary coupling and the altered boundary condition of far-field velocity. Taking advantage of the required force balance, the motion of the sphere as a function of $F_{e x t}$ may be written as;

$$
\left(\mathrm{f}_{1} \mathrm{U}_{\mathrm{s}}-\mathrm{f}_{2} \mathrm{U}_{\mathrm{f}}\right)=\mathrm{F}_{\text {ext }} /\left(6 \pi \mu \mathrm{R}_{\mathrm{s}}\right) .
$$

The difference between $F_{\text {drag }}$ and $F_{\text {drag }}$ can best be appreciated for the case when $F_{\text {ext }}$ is zero, so that fluid drag is also zero. As shown previously (Eq. 2), $U_{s}=U_{f l}$ under such circumstances. However, it can be seen from Eq. (4) that $U_{s}=\left(f_{2} / f_{1}\right) U_{f l}$ when $F_{e x t}=0$. Consequently, $\mathrm{U}_{\mathrm{s}} \neq \mathrm{U}_{\mathrm{f}}$ in the vicinity of a solid boundary, and the particle diverges from the streamline. Under most circumstances, the presence of the solid boundary will 'push' the sphere up off its original streamline. This boundary effect, often interpreted as a repulsive hydrodynamic interaction or hydrodynamic retardation force (Spielman 1977), is present in addition to the pure Stokes drag component. As $h / R_{p}$ goes to infinity, $f_{1}$ and $\mathrm{f}_{2}$ go to unity. Therefore, for an infinitely small sphere or a sphere far from a solid boundary, relative to its radius, $F_{\text {drag }}^{\prime}=F_{\text {drag }}$, and the sphere is expected to follow the fluid streamlines in the absence of any $F_{\text {ext }}$. Using $F^{\prime}$ drag to describe the fluid drag, Goren \& O'Neill (1971) showed that for the special case when a small spherical particle approaches a large spherical collector, the small sphere follows the fluid streamline until it comes within ca 2.5 particle radii from the collector.

\section{Surface forces}

In the previous section we outlined an approach for determining the motion of a sphere through a fluid as a function of applied external forces (Eq. 4). We now consider those external forces believed to be important to the direct-interception process. For zooflagellatepicoplankton interactions the force of gravity can be ignored, leaving molecular interactions between surfaces (i.e. surface-forces) as the dominant components of $F_{\text {ext }}$. These surface-forces are generally arranged into 3 basic groups: electrodynamic-electrostatic, solvation, and steric forces. The magnitude and spatial variation of each of these force components have complex dependencies on the chemical composition and geometry of the surface material as well as the chemical nature of the fluid within which the surface is immersed. As an important point, the effects of electrodynamic (van der Waals) and electrostatic forces on aggregation of colloid particles have been studied extensively, over the past 50 yr resulting in the celebrated Derjaguin-Landau-Verwey-Overbeek (DLVO) theory for colloid stabilization (Derjaguin \& Landau 1941, Verwey \& Overbeek 1948, Hiemenz 1986). According to DLVO theory, the attractive van der Waals forces and the repulsive electrostatic forces act alone to determine if particles will be repulsed (stabilized) or attracted (aggregated). Recent advances, however, have revealed that solvation and steric forces may make an important contribution to colloid stability, and that deviations from the predictions of the DLVO theory can generally be attributed to the presence of these other forces rather than a break down in the DLVO theory (Israelachvili \& McGuiggan 1988). We briefly describe the origin of these surface-force components and compare force-distance relationships to one other. From this comparison we argue that at surface separation distances greater than $5 \mathrm{~nm}$ attractive London-van der Waals force dominates and at separations less than $3 \mathrm{~nm}$ a repulsive hydration force dominates.

Van der Waals forces. At any instant, even neutral atoms have instantaneous dipole moments generating an electric field which, in turn, polarizes nearby neutral atoms. The resulting interaction between the 2 dipoles gives rise to an instantaneous attractive force between atoms. The time-averaged force is the van der Waals force which is divided into 3 component forces; Keesom (orientation), Debye (induction), and London (dispersion) (Israelachvili \& Tabor 1973). Keesom and Debye forces are not important in high ionic strength solutions due to screening effects (Silver 1985). However, the London-van der Waals force (FLondon) is little affected by the presence of ions in solution and thus becomes the dominate component of the net van der Waals force between surfaces in seawater.

The theory behind the van der Waals force is well defined for isolated atoms in vacuum, but extending this theory to condensed media (i.e. macroscopic surfaces) requires significant assumptions to account for the interactions between neighboring atoms. Three separate approaches to estimating the van der Waals force predominate. The results from these 3 methods are often presented as non-retarded Hamaker 'constants' (Q) specific to given surface compositions (Hamaker 1937). Such constants can then be used to predict the van der Waals force for other surface geometries with similar composition (e.g. cylinders, spheres, flat planes). $Q$ is not strictly constant but rather a decreasing function of separation distance. This decrease is due to retarding effects brought about by the finite travel time of an electromagnetic signal and the corresponding phase shift (Silver 1985). Nonetheless, $Q$ is widely used in the colloid literature as a reasonable approximation.

The Lifshitz or continuum approach predicts the van der Waals force from optical data and theoretical com- 
putations (Lifshitz 1956, Israelachvili \& Tabor 1973). Because optical measurements can be taken directly from a surface, the Lifshitz approach accounts for interactions among neighboring atoms. Alternatively, a direct-force measuring device (Israelachvili \& Adams 1978) has been used to determine force-distance relationships between lipid bilayers adsorbed onto mica plates (Marra \& Israelachvili 1985, Marra 1986). Finally, Parsegian et al. (1979) developed a means of controlling the osmotic pressure between 2 surfaces by addition of high molecular weight solutes. A forcedistance relationship can be determined from the equilibrium separation between 2 surfaces as a function of the osmotic pressure.

The magnitude of the Hamaker constant for the van der Waals force for lipid bilayers in seawater (i.e. London force) appears to be well constrained by these 3 techniques. Using optical data and Lifshitz theory, $Q$ was found to range from 1 to $4 \times 10^{-21} \mathrm{~J}$ (Israelachvili 1985 ) and from 0.9 to $6.4 \times 10^{-21} \mathrm{~J}$ (Nir 1976). To adjust literature values of $Q$ measured in pure water to reflect the $Q$ expected in seawater, Keesom and Debye components must be subtracted. According to theory (Mahanty \& Ninham 1976) and observation (Marra \& Israelachvili 1985) this reduces the observed $Q$ by about $3 \times 10^{-21} \mathrm{~J}$. Using this approach we obtain the following 'adjusted values' of $Q$. From the direct force measuring technique, $Q=4 \times 10^{-21} \mathrm{~J}$ (Marra \& Israelachvili 1985). Using the osmotic stress technique, $\mathrm{Q}=3 \times 10^{-21} \mathrm{~J}$ (Parsegian et al. 1979) and $4.9 \times 10^{-21} \mathrm{~J}$ (Lis et al. 1982). A reasonable mean estimate for the non-retarded Hamaker constant for general lipid bilayer systems in seawater is therefore $3.7 \times 10^{-21} \mathrm{~J}$.

Electrostatic double-layer forces. When particles are immersed in water, many of their surface groups may dissociate (e.g. dissociation of protons from surface carboxylic groups), producing a negatively charged surface. Furthermore, ions in solution may adsorb onto particle surfaces to alter net surface charge. Observations of electrophoretic mobilities of marine particulate matter composed of detritus and microorganisms range from -0.6 to $-1.0 \times 10^{-8} \mathrm{~m}^{2} \mathrm{~s}^{-1} \mathrm{~V}^{-1}$ (Hunter 1980). These mobilities, in turn, can be related to the electric potential at the plane of fluid shear using the Helmholtz-Smoluchowski relation (Hiemenz 1986) to yield $\zeta$ potentials $<25 \mathrm{mV}$. Hunter (1980) observed no particles with positive mobilities (i.e. positive charge). Similarly, Gerritsen \& Bradley (1987) measured only negative mobilities on pure cultures of a freshwater cyanobacteria, chlorophyte and heterotrophic bacteria which averaged $-2.0 \times 10^{-8} \mathrm{~m}^{2} \mathrm{~s}^{-1} \mathrm{~V}^{-1}$ with corresponding $\zeta$-potentials $<40 \mathrm{mV}$. While $\zeta$-potentials are somewhat lower than the actual surface potentials, the fundamental conclusions we develop below will not be altered by this approximation.
In response to the electric potential produced by charged surface, counter ions will concentrate as described by the Poisson-Boltzmann equation. The elevated concentration of ions between 2 charged surfaces lowers the chemical potential of the water resulting in an increase in osmotic pressure which, in turn, produces a repulsive force between the surfaces (electric double-layer repulsion). The effect of high concentration of electrolytes in the bulk medium is to confine the double layer of ions, and associated repulsion, very near the surfaces where van der Waals force dominates.

An expression for the potential energy associated with the electric double-layer has been derived for surface potentials $<50 \mathrm{mV}$ (Hogg et al. 1966) which upon differentiation (Fitzpatrick 1972) yields an expression for the double-layer force as a function of separation distance. If we use the expression of Fitzpatrick (1972), assuming $\zeta$-potentials of $40 \mathrm{mV}$, seawater ionic strength $(0.7 \mathrm{M})$, and a London-van der Waals force given by Eq. (13) $\left(\mathrm{Q}=3.7 \times 10^{-21} \mathrm{~J}\right)$, then the ratio of double-layer to London-van der Waals force will be $<10^{-2}$ and $<10^{-5}$ for separations $>3 \mathrm{~nm}$ and $>5 \mathrm{~nm}$ respectively. Therefore, at separations greater than $3 \mathrm{~nm}$, the electric double-layer force may be justifiably neglected. Of course, for limnitic systems the electric double layer force may be comparable to or greater than London-van der Waals force.

Solvation forces. Solvation forces are a general class of forces attributable to changes in the work of solvation of 2 surfaces as they approach one other. The net solvation force is comprised of 'short-range' and 'longrange' components; both are a functions of separation distance between surfaces. The short-range component is further composed of a 'structural' component, which oscillates with separation distance between attraction and repulsion, and a repulsive 'hydration' component, which decays monotonically with separation distance (McGuiggan \& Pashley 1988). The structural solvation force is probably unimportant for cell surfaces because this force has only been observed for molecularly smooth and weakly hydrated surfaces; neither of which describe lipid bilayer systems (Marra 1986).

The repulsive hydration force component arises from the work required to dehydrate hydrophilic groups in lipid bilayers and has been measured by separate methods for both neutral and charged lipids (LeNeveu et al. 1976, Cowley et al. 1978, Parsegian et al. 1979, Lis et al. 1982, Horn 1984, Marra \& Israelachvili 1985, Marra 1986). With few exceptions, this hydration force exhibits very strong repulsion near the surface and rapid exponential decay with separation distance (decay length 0.2 to $0.3 \mathrm{~nm}$ ). The repulsive hydration force dominates all other forces at separations $<3 \mathrm{~nm}$, 
but is generally negligible at separations $>5 \mathrm{~nm}$, at which point DLVO predictions are good (Silver 1985. McGuiggan \& Pashley 1988). While bilayers of different lipid composition exhibit similar decay rates, they differ markedly in their strengths (Lis et al. 1982) and therefore, a general expression for the hydration force cannot be incorporated into an interception model without knowing the composition of the cell surfaces involved. Nonetheless, because of the rapid rate of decay and the fact that below about $3.0 \mathrm{~nm}$ the repulsion rapidly dominates other forces, this force can be approximated as a step function providing a repulsive 'wall' at $3.0 \mathrm{~nm}$ that prevents closer approach.

The long-range solvation component is an attractive force arising between interacting hydrophobic surfaces and is most often referred to as a hydrophobic interaction force. It is believed to arise from the orientational rearrangement of water molecules, and their associated $\mathrm{H}$-bonds, as hydrophobic surfaces approach one another (Israelachvili 1987, Israelachvili \& McGuiggan 1988). Direct measurements of this interaction force indicate that it is very strongly attractive but decays exponentially (decay length ca $1.0 \mathrm{~nm}$ ) (Israelachvili \& Pashley 1982, Pashley et al. 1985). The hydrophobic force makes a significant contribution to the total surface force at separations up to 10 or $15 \mathrm{~nm}$, although this attractive force is inexplicably lost when hydrophilic and hydrophobic groups are present on the same surface (Israelachvili 1987). This may explain why significant long-range attractive forces have not been measured in lipid bilayer systems (Israelachvili 1987). The importance of the bacterial cell wall, or the glycocalyx of eukaryotic cells, on the hydrophobic interaction force is not well understood (Evans \& Ninham 1986). As a result, this force cannot be incorporated into an interception model at this time and remains an important area for future research.

Steric forces. Cell membranes are complex structures composed of a bilayer matrix of mixed lipids interspersed with proteins. In eukaryotic cells there is a special group of lipids and proteins (glycolipids \& glycoproteins) which have large hydrophilic oligosaccharide groups extending above the cell surface to form a diffuse, carbohydrate-rich, glycocalyx (Lehninger 1982). In prokaryotes, the cytoplasmic membrane is surrounded by a rigid cage-like structure called a peptidoglycan. In gram-negative bacteria, which are the principal forms in the marine environment, the peptidoglycan is covered by a lipid-rich outer membrane. Electron micrographs of Escherichia coli (a gram-negative cell), prepared by a freeze-etching technique, showed the outer surface to be smooth with scattered bumps. However, it is also true that thin hairlike structures called fimbriae are commonly observed among gram-negative bacteria, including $E$. coli
(Rogers 1983). The forces associated with the interaction of these surface asperities are called steric forces. These forces have been studied extensively in the colloid literature for surfaces with adsorbed polymeric substances. Steric forces arise when the diffuse layers of polymeric substance overlap as surfaces approach one other. In 'good' solvents (mixing of polymer with solvent thermodynamically favorable) the overlap leads to repulsion while in 'poor' solvents attraction occurs. At closer approach, finite-volume effects caused by the compression of the polymeric substances produce a repulsive force (Israelachvili 1985). The above description of steric interactions is a great simplification of a complex process in which important details remain controversial. Nonetheless, the FloryKrigbaum theory, which can yield quantitative results, is often presented as a starting point in introductory texts (Hiemenz 1986). While the details of this model are beyond the scope of this paper, it should be noted that the model requires knowledge of the length, surface concentration, and the change in free energy of mixing of the polymers. To our knowledge, none of these parameters is known for the surfaces of marine bacteria or protozoa. Therefore, incorporation of this potentially important force into a interception model cannot be made at this time. However, it is encouraging that once these parameters are obtained, they can be incorporated into the current theoretical framework to yield more accurate predictions of the interception process

\section{Approximated Force-Balance modeI of direct-interception}

Thus far it has been shown that, at low Re, there exists a balance between fluid drag and externally applied forces $\left(\mathrm{F}_{\text {drag }}^{\prime}+\mathrm{F}_{e x t}=0\right)$ which allows $\mathrm{F}^{\prime}$ drag to be determined from a given $F_{\text {ext }}$. In turn, the motion of a particle is uniquely related to $F^{\prime}{ }_{\text {drag }}$ through the Stokes equations. While accurate expressions for these forces will yield accurate predictions of motion and thus interception rates, it was shown above that not all components of $\mathrm{F}_{\text {ext }}$ can be incorporated into an interception model at this time. Nonetheless, we propose a reasonable 'Force-Balance' (FB) model of first order approximation to test against observation.

The model presented below neglects hydrophobic and steric forces due to insufficient theory and/or quantitative data. Of the remaining forces, only London-van der Waals and hydration forces are important in seawater medium. Presumably the hydration force acts as a repulsive barrier situated ca $3 \mathrm{~nm}$ from a surface whereas the attractive London van der Waals dominates at separations $>5 \mathrm{~nm}$. As a result, a potential energy minimum exists somewhere between 3 and 
$5 \mathrm{~nm}$ whereupon approaching surfaces are expected to come to rest. Quite clearly contact and subsequent engulfment does occur; possibly mediated by recognition of specific molecules on the surface of the prey by receptor molecules on the surface of the grazer Two examples of such specific interactions are antibodyantigen and lectin-sugar interactions (see Bell 1988). Following recognition and 'acceptance', there are a number of proposed mechanisms to overcome the hydration force: (a) intrabilayer lateral pressure increases, affecting molecular interactions within a bilayer; (b) segregation of bilayer components can occur in mixed lipid bilayers (i.e. hydrophilic head groups can migrate out of the contact area); (c) disruption of the bilayer and complete rearrangement of its molecules (Rand 1981).

If it is assumed that the time required to recognize and engulf a prey is short compared to prey encounter time, as would be the case for food-limited situations, then modeling forces up to the primary minimum region (ca $3 \mathrm{~nm}$ ) can be used to predict ingestion rates of 'selected' prey. It can be shown (see 'Materials and methods' section) that the distance of closest approach of a critical trajectory is greater than $5 \mathrm{~nm}$ under conditions typical of zooflagellate-picoplankton interactions Since the nature of the critical trajectory determines the clearance rate, it can be assumed that model predictions of selected prey will not be affected by the presence of the hydration barrier. In this manner, we choose to approximate the net external force with the London-van der Waals force. If we further choose to approximate the shape of picoplankton and zooflagellate as spheres and ignore the effects of flagellar motion we can utilize a previously published model of interception of small spherical particles from a fluid moving slowly past a large spherical collector (Spielman \& Goren 1970).

Considering only the $F_{\text {London }}$ component and fluid drag, Spielman \& Goren (1970) demonstrated that the nature of the direct-interception process is dependent on the relative strengths of the attractive $F_{\text {London }}$ and the repulsive hydrodynamic interaction component of the net fluid drag. The ratio of these forces is roughly expressed by a dimensionless adhesion number $\left(\mathrm{N}_{\text {ads }}\right)$ given by:

$$
N_{a d s}=Q_{g}{ }^{2} /\left(9 \pi \mu U_{g} R_{p}^{4}\right)
$$

For the limiting cases $N_{a d s} \gg 1$ and $N_{a d s} \ll 1$, approximate analytical solutions for prey trajectories are obtainable. For conditions typical of zooflagellate-picoplankton interactions, however, intermediate values of $N_{\text {ads }}(0.01$ to 150$)$ require numerical methods to solve for prey trajectories.

A special case of the general Force-Balance model arises if $F_{\text {ext }}$ is ignored and prey radius $\left(R_{p}\right)$ is assumed to be infinitely small (i.e. $F_{\text {drag }}$ is used to represent fluid drag). Under these circumstances, $U_{p}=U_{g}$ (Eq. 2) and the prey follows the fluid streamlines around the grazer. This is precisely the Geometric model utilized by Fenchel (1982a). Fig. 1 provides a qualitative comparison between the Force-Balance and Geometric models. Two possibilities exist for the Force-Balance model. If the repulsive hydrodynamic interaction force is large relative to any surface attractive force, the approaching prey will be pushed off the streamline away from the collector. However, if the repulsive hydrodynamic interaction force is small relative to the surface attractive force, the prey will spiral off the streamline into the collector surface. In the former case, the Geometric model overestimates clearance rates, and in the latter, it underestimates clearance rates.

In Spielman \& Goren's (1970) analysis, and in subsequent analyses of similar problems (Goren \& O'Neill 1971, Fitzpatrick 1972, Spielman \& Fitzpatrick 1973, Spielman 1977), the parameters $f_{1}$ and $f_{2}$ were determined using a flat-plane approximation for a curved collector surface. The approximated form of the wallcorrected fluid drag ( $F^{\prime \prime}{ }_{\text {drag }}$ ) simplifies the mathematics and allows analytical solutions for the limiting cases, but it restricts the model's usefulness to the case where $\mathrm{R}_{\mathrm{p}} \ll \mathrm{R}_{\mathrm{g}}$. Nonetheless, error analysis (Goren \& O'Neill 1971 ) indicates that $F^{\prime \prime}$ drag is accurate to order $R_{p} / R_{g}$.

\section{MATERIALS AND METHODS}

We use the approach of Spielman \& Goren (1970) to determine critical trajectories of prey moving toward an individual grazer. Due to errors introduced by using the flat-plane approximation (see 'Discussion'), results are limited to grazer-prey size combinations in which $0.03<\mathrm{R}_{\mathrm{p}} / \mathrm{R}_{\mathrm{g}}<0.3$. We consider this to be a practical range about the value of ca 1:10 generally held to apply to predator-prey size ratios in the microbial food web (Azam et al. 1983). The lower limit of $R_{p} / R_{g}$ has an additional constraint that $R_{p} \geq 0.1 \mu \mathrm{m}$. Similarly, for large grazers, the upper limit of $R_{p} / R_{g}$ is constrained by $R_{p} \leq 0.75 \mu \mathrm{m}$. The computations describing the Spielman \& Goren (1970) model have been presented by Fitzpatrick (1972) in the form of a FORTRAN code which we use with slight modification as outlined below. A copy of this modified code is available upon request.

Stokes' stream function for the undisturbed flow around the 'spherical' grazer has been approximated by Happel (1959) as:

$$
\Psi=(3 / 2) U_{g} \sin ^{2}(\theta)\left(r-R_{g}\right)^{2}
$$

from which the velocity components $U_{\theta}$ and $U_{r}$ are determined. To make use of existing wall-corrected Stokes' drag equations, the undisturbed flow within a 
small region at a given point near the grazer surface is decomposed into the sum of a stagnation point flow $\left(\mathrm{U}_{\text {stag }}\right)$ and a linear shear flow $\left(\mathrm{U}_{\text {shr }}\right)$ about a tangent plane at $\left(r=R_{g}, \theta=\theta_{p}\right)$. The $U_{\text {stag }}$ and $U_{\text {shr }}$ are derived from $U_{\theta}$ and $U_{r}$ by expansion through terms of second order about $\left(r=R_{p}, \theta=\theta_{p}\right)$ and expressed by

$$
\begin{gathered}
U_{\text {stag }}=(3 / 2) U_{g} \cos \left(\theta_{p}\right)\left(y z i_{Y}-z^{2} i_{z}\right) / R_{s}{ }^{2} \\
U_{s h r}=(3 / 2) U_{g} \sin \left(\theta_{p}\right) z i_{x} / R_{s}
\end{gathered}
$$

where the subscripts $x, y$ and $z$ refer to the components of a right-handed coordinate system of a tangent plane located on the grazer surface. The net force on a small sphere in these flows is broken down into normal and tangential components $\left(F_{n o r}, F_{t a n}\right)$ which also include the London-van der Waals force $\left(F_{\text {London }}\right)$. Recall, $F_{\text {nor }}$ and $F_{t a n}$ equal zero when $R e \ll 1$ (see 'Theoretical considerations'). The separate force components are expressed by,

$$
\begin{gathered}
F_{\text {nor }}=F_{\text {stag }}+F_{\text {London }}+F_{h r}=0 \\
F_{\text {tan }}=F_{\text {shr }}=0
\end{gathered}
$$

where $\mathrm{F}_{\mathrm{hr}}=$ the normally directed hydrodynamic resistance force caused by the motion of the prey relative to the surface of the grazer (see 'Discussion'). F Fhr has been previously determined from exact solutions to Stokes' equations incorporating hydrodynamic resistance for a sphere freely translating and rotating (i.e. zero net force and torque) in a linear shear-flow near a flat wall (Goldman et al. $1967 a_{1} b$ ). For $F_{\text {stag, it is neces- }}$ sary to separate out the effects of translation (rotation is zero due to the symmetry of $U_{\text {stag }}$ ) so that hydrodynamic resistance to translation produced by $F_{\text {London }}$ can also be included. This procedure is valid due to the linearity of Stokes' equations. Using Stokes' equations, $F_{\text {stag }}$ has been determined for a stationary sphere in a stagnation point flow near a flat plane (Goren 1970) and $F_{h r}$ for a sphere approaching a flat plane in a stationary fluid (Brenner 1961). Fondon was determined by Hamaker (1937) for a sphere near a flat plane using a mean nonretarded Hamaker constant (Q) of $3.7 \times 10^{-21} \mathrm{~J}$. A mean zooflagellate swimming speed $\left(U_{4 y}\right)$ of $200 \mu \mathrm{m} \mathrm{s}^{-1}$ was used based on arguments of Fenchel (1987). The 4 force components used in this model have the form;

$$
\begin{gathered}
F_{\text {stag }}=6 \pi \mu R_{p} U_{\text {stag }} f_{2}(\mathrm{H}), \\
F_{h r}=\left(d z_{p} / d t\right) 6 \pi \mu R_{p} f_{1}^{-1}(H), \\
F_{\text {London }}=-2 Q / 3 R_{p}(H+2)^{2} H^{2}, \\
F_{\text {tan }}=\left(d x_{p} / d t\right)-R_{p} U_{\text {shr }}(H+1) \mathrm{f}_{3}(\mathrm{H})=0,
\end{gathered}
$$

where $z_{p}=$ the distance of the prey center to the grazer surface; and $H=h / R_{p}$, where $h=z_{p}-R_{p}$ (i.e. the gap distance between grazer and prey surfaces). Selected values of $\mathrm{f}_{1}(\mathrm{H}), \mathrm{f}_{2}(\mathrm{H}), \mathrm{f}_{3}(\mathrm{H})$ as listed by Fitzpatrick
(1972) are presented, along with limiting analytical forms, in Table 1.

Using Eqs. (7) to (14), $\mathrm{d} z_{\mathrm{p}} / \mathrm{dt}$ and $\mathrm{d} \theta_{\mathrm{p}} / \mathrm{dt}$ are solved algebraically. Noting $\mathrm{d} z_{\mathrm{p}} / \mathrm{dt}=\mathrm{R}_{\mathrm{p}} \mathrm{dH} / \mathrm{dt}$ and $\mathrm{d} \theta_{\mathrm{p}} / \mathrm{dt}=$ $\left(1 / R_{g}\right) d x_{p} / d t$, and eliminating the time dependency between these 2 derivatives, yields the following expression,

$$
\begin{aligned}
& d H / d \theta_{p}=\left\{f_{1}(H) f_{2}(H)(H+1) / f_{3}(H)\right\} \cot \left(\theta_{p}\right)- \\
& 2 f_{1}(H) N_{a d s} / 3 \sin \left(\theta_{p}\right) f_{3}(H)(H+1)(H+2)^{2} H^{2},
\end{aligned}
$$

where $N_{a d s}$ is given by Eq. (5).

Because - dH/d $\theta_{p}$ goes to infinity as $\mathrm{H}$ goes to zero, 'capture' trajectories are perpendicular at the surface of the zooflagellate. The limiting trajectory (that which brings the prey closest to the zooflagellate without capture) occurs at $d H / d \theta_{p}=0$. Setting Eq. (15) to zero and rearranging yields $H=H\left(\theta_{p}, N_{a d s}, f_{1,}, f_{2}, f_{3}\right)$ which is minimized for $\theta_{p}=\pi$. Therefore, closest approach $\left(\mathrm{H}^{*}\right)$ occurs at the rear of the zooflagellate. The magnitude of $\mathrm{H}^{*}$ is determined for a given $\mathrm{N}_{\text {ads }}$ by setting Eq. (15) to zero, $\theta_{p}=\pi$ and solving for the roots using a Muller iteration method (Gerald 1980, p. 60-61) which replaces subroutine DRTMI used by Fitzpatrick (1972). Spline fitting was used to determine $f_{1}, f_{2}$ and $f_{3}$ between tabulated points.

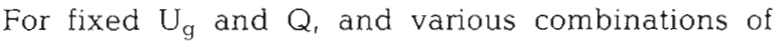
$R_{p}$ and $R_{g}$ an $N_{a d s}$ is determined and subsequently, $H^{*}$. Eq. (15) is then numerically integrated along a trajectory beginning at $\left(\mathrm{H}^{*}, \pi\right)$, using a fourth-order RungeKutta algorithm. Integration is terminated when $\mathrm{H}=$ 100 (i.e. $h=100 R_{p}$ ) where it effectively coincides with an undisturbed streamline. At the beginning of the integration $\theta_{\mathrm{p}}$ step-size is $-1.0 \times 10^{-6}$ and is increased by $-1.0 \times 10^{-6}$ after each iteration until it reaches $-0.1 \%$ of the current $\theta_{p}$. It is kept at this constant percentage thereafter.

Because $-\mathrm{dH} / \mathrm{d} \theta_{\mathrm{p}}$ approaches infinity as $\theta_{\mathrm{p}}$ approaches 0 , the algorithm diverges for small $\theta_{p}$. For this reason, the dependent and independent variables are switched when $-\mathrm{dH} / \mathrm{d} \theta_{\mathrm{p}}=1$ at $\left(\mathrm{H}^{\prime}, \theta_{\mathrm{p}}{ }^{\prime}\right) \cdot \mathrm{d} \theta_{\mathrm{p}} / \mathrm{dH}$ is then integrated from this point, using the formula

$$
\begin{aligned}
& d \theta_{p} / d H=-(2 / 3) f_{3}(H)(H+1) \sin \left(\theta_{p}\right) / f_{1}(H) \\
& \quad\left\{(2 / 3) f_{2}(H)(H+1)^{2} \cos \left(\theta_{p}\right)+N_{a d s} /(H+2)^{2} H^{2}\right\}
\end{aligned}
$$

with a step-size $=0.1 \% \mathrm{H}^{\prime}$. The magnitude of the stepsize is increased by $0.1 \% \mathrm{H}^{\prime}$ after each iteration until the magnitude of the step is $0.1 \%$ of the current $H$. It is kept at this constant percentage thereafter.

Following arguments made in the discussion, clearance rate is equivalent to the volume flux between the axis of symmetry and the streamline representing the critical prey trajectory in the undisturbed flow forward of the grazer. Recalling that the volume flux between a Stokes Streamline $(\Psi)$ and the axis of symmetry is given by $2 \pi \Psi$, we take the values of $\mathrm{H}$ and $\theta_{\mathrm{p}}$ at the 
Table 1. Tabulated values and limiting analytical forms of wall-correction factors to Stokes drag equations as compiled by Fitzpatrick (1972). See text for explanation of $f_{1}, f_{2}$ and $f_{3}$

\begin{tabular}{|c|c|c|c|c|c|c|c|}
\hline $\mathrm{H}=\mathrm{h} / \mathrm{Rp}$ & $\mathrm{f}_{1}(\mathrm{H})$ & $\mathrm{f}_{2}(\mathrm{H})$ & $\mathrm{f}_{3}(\mathrm{H})$ & $\mathrm{H}=\mathrm{h} / \mathrm{Rp}$ & $\mathrm{f}_{1}(\mathrm{H})$ & $f_{2}(H)$ & $\mathrm{f}_{3}(\mathrm{H})$ \\
\hline 0.0000 & $(1)^{\mathrm{c}}$ & 3.2292 & $(2)^{\mathrm{d}}$ & 0.1276 & & 2.8891 & \\
\hline $1.0000 \times 10^{-4}$ & & & 0.3185 & 0.1300 & & & 0.7690 \\
\hline $2.0000 \times 10^{-4}$ & & & 0.3360 & 0.1500 & & & \\
\hline $3.0000 \times 10^{-4}$ & & & 0.3486 & 0.1750 & & & 0.8030 \\
\hline $4.0000 \times 10^{-4}$ & & & 0.3587 & 0.2000 & 0.15771 & 2.7300 & 0.8178 \\
\hline $5.0000 \times 10^{-4}$ & & & 0.3670 & 0.2500 & 0.18849 & & 0.8420 \\
\hline $6.0000 \times 10^{-4}$ & & & 0.3742 & 0.2600 & & 2.6150 & \\
\hline $7.0000 \times 10^{-4}$ & & & 0.3803 & 0.2750 & & & 0.8525 \\
\hline $8.0000 \times 10^{-4}$ & & & 0.3862 & 0.3000 & & & 0.8618 \\
\hline $9.0000 \times 10^{-4}$ & & & 0.3916 & 0.3200 & & 2.5120 & \\
\hline $1.0000 \times 10^{-3}$ & & & 0.3966 & 0.3500 & 0.24320 & & 0.8787 \\
\hline $1.2000 \times 10^{-3}$ & & & 0.4058 & 0.3800 & & 2.4240 & \\
\hline $1.4000 \times 10^{-3}$ & & & 0.4138 & 0.4000 & & & 0.8930 \\
\hline $1.6000 \times 10^{-3}$ & & & 0.4207 & 0.4400 & & 2.3480 & \\
\hline $1.8000 \times 10^{-3}$ & & & 0.4267 & 0.4500 & & & 0.9053 \\
\hline $2.0000 \times 10^{-3}$ & & & 0.4319 & 0.5000 & 0.31197 & 2.2820 & 0.9157 \\
\hline $2.3000 \times 10^{-3}$ & & & 0.4386 & 0.5430 & & 2.2395 & \\
\hline $2.6000 \times 10^{-3}$ & & & 0.4439 & 0.5500 & & & 0.9250 \\
\hline $2.9000 \times 10^{-3}$ & & & 0.4484 & 0.6000 & & 2.1830 & 0.9335 \\
\hline $3.2020 \times 10^{-3}$ & & & 0.4529 & 0.7000 & & 2.0880 & 0.9478 \\
\hline $3.6000 \times 10^{-3}$ & & & 0.4589 & 0.7500 & 0.40172 & & \\
\hline $4.0000 \times 10^{-3}$ & & & 0.4642 & 0.8000 & & 2.0160 & 0.9582 \\
\hline $4.5000 \times 10^{-3}$ & & & 0.4712 & 0.9000 & & 1.9410 & 0.9655 \\
\hline $5.0640 \times 10^{-3}$ & & 3.2119 & 0.4786 & 1.0000 & 0.47047 & 1.8700 & 0.9704 \\
\hline $6.0000 \times 10^{-3}$ & & & 0.4900 & 1.1000 & & 1.8320 & \\
\hline $7.0000 \times 10^{-3}$ & & & 0.5000 & 1.1500 & & & 0.9746 \\
\hline $8.0000 \times 10^{-3}$ & & & 0.5090 & 1.2000 & & 1.7780 & \\
\hline $9.0000 \times 10^{-3}$ & & & 0.5170 & 1.2500 & 0.52500 & & \\
\hline 0.0100 & 0.00981 & & 0.5245 & 1.3000 & & 1.7370 & 0.9768 \\
\hline 0.0120 & & & 0.5380 & 1.3520 & & 1.7173 & \\
\hline 0.0140 & & & 0.5495 & 1.4000 & & 1.6990 & \\
\hline 0.0150 & 0.01460 & & & 1.5000 & 0.56936 & 1.6650 & 0.9800 \\
\hline 0.0160 & & & 0.5600 & 1.7000 & & 1.6020 & \\
\hline 0.0180 & & & 0.5695 & 1.7500 & & & 0.9824 \\
\hline 0.0200 & 0.01932 & & 0.5785 & 1.9000 & & 1.5500 & \\
\hline 0.0230 & & & 0.5900 & 2.0000 & 0.63727 & & 0.9860 \\
\hline 0.0250 & 0.02397 & & & 2.2000 & & 1.4870 & \\
\hline 0.0260 & & & 0.6015 & 2.4000 & & & 0.9902 \\
\hline 0.0290 & & & 0.6115 & 2.5000 & 0.68680 & 1.4380 & \\
\hline 0.0330 & & & 0.6237 & 2.7620 & & 1.3995 & \\
\hline 0.0350 & 0.03309 & & & 2.7622 & & & 0.9943 \\
\hline 0.0370 & & & 0.6345 & 3.0000 & 0.72453 & 1.3660 & \\
\hline 0.0410 & & & 0.6445 & 3.2500 & & 1.3370 & \\
\hline 0.0453 & & 3.0960 & 0.6537 & 3.5000 & & 1.3140 & \\
\hline 0.0500 & 0.04633 & & 0.6640 & 4.0000 & 0.77816 & 1.2750 & \\
\hline 0.0550 & & & 0.6740 & 5.0000 & 0.81441 & 1.2200 & \\
\hline 0.0600 & & & 0.6830 & 6.0000 & 0.84052 & 1.1860 & \\
\hline 0.0700 & 0.06325 & & 0.7000 & 7.0000 & 0.86030 & 1.1610 & \\
\hline 0.0800 & & 3.0050 & 0.7145 & 8.0000 & 0.87570 & 1.1420 & \\
\hline 0.0900 & & & 0.7280 & 9.0000 & 0.88750 & & \\
\hline 0.1000 & 0.08727 & & 0.7395 & 9.0677 & $(3)^{a}$ & 1.1257 & 0.9996 \\
\hline 0.1100 & & & 0.7505 & $\infty$ & & $(4)^{\mathrm{a}}$ & $(5)^{a}$ \\
\hline 0.1200 & & & 0.7610 & & & & \\
\hline
\end{tabular}


time the integration is halted $\left(\mathrm{H}_{\mathrm{f}}, \theta_{\mathrm{p}_{\mathrm{f}}}\right)$, and determine the value of the streamline passing through that point using Eq. (6). Making the suitable change of variables in Eq. (6) yields $\Psi^{\prime}\left(\mathrm{H}_{1} \theta_{\mathrm{p}}\right)$ and the following expression:

$$
\begin{gathered}
C l r=2 \pi \Psi^{\prime}\left(H_{f}, \theta_{p_{f}}\right) \\
=2 \pi\left\{(3 / 2) R_{p}{ }^{2} U_{g}\left(H_{f}+1\right)^{2} \sin ^{2}\left(\theta_{p_{f}}\right)\right\}
\end{gathered}
$$

The resulting model was run with the Microsoft FORTRAN compiler using double precision numbers on a Macintosh SE/30. Graphics were displayed using SYGRAPH software (Evanston, IL, USA). In verifying the accuracy of trajectory calculations, estimates of $\mathrm{H}^{*}$ obtained from Muller iteration were identical to tabulated values given by Fitzpatrick (1972) for various values of the dimensionless adhesion number $\left(\mathrm{N}_{\text {ads }}\right)-$ as defined above. In addition, no differences were found between particle trajectories determined from our model $\left(\mathrm{N}_{\mathrm{ads}}=1.0\right)$ and those listed by Fitzpatrick (1972).

Clearance rate estimates for the $\mathrm{FB}$ model $\left(\mathrm{Clr}_{\mathrm{FB}}\right.$ ) were calculated for $\mathrm{R}_{\mathrm{g}}=1$ to $5 \mu \mathrm{m}$ at $0.25 \mu \mathrm{m}$ increments. We also varied $R_{p}$ from 0.05 to $0.75 \mu \mathrm{m}$ at $0.05 \mu \mathrm{m}$ increments except in the model sensitivity analysis where $R_{\mathrm{g}}$ and $\mathrm{R}_{\mathrm{p}}$ increments were 1 and $0.1 \mu \mathrm{m}$ respectively. Clearance rate estimates for the Geometric model ( $C \mathrm{r}_{\mathrm{GEO}}$ ) were calculated from the formula $\mathrm{Clr}_{G E O}=(3 / 2) \pi \mathrm{U}_{\mathrm{g}} \mathrm{R}_{\mathrm{p}}{ }^{2}$ (Spielman 1977).

The effect of prey size on $\mathrm{Clr}_{\mathrm{FB}}$ for a given $\mathrm{R}_{\mathrm{G}}$ was determined by expressing the measured clearance rate in the form $c_{1} R_{p} X_{1}$ (where $c_{1}$ is a constant) and solving for $X_{1}$. The value of $X_{1}$ at $R_{p}$ was calculated from the slope of the least squares regression through $\log \left(\mathrm{Clr}_{\mathrm{FB}}\right)$ vs $\log \left(R_{p}\right)$ using the 3 points, $R_{p}$ and $R_{p} \pm 0.1 \mu m$. The effect of grazer size on clearance rate was determined in an analogous manner by holding $R_{p}$ constant and regressing through $R_{g}$ and $R_{g} \pm 0.5 \mu \mathrm{m}$.

We examined the sensitivity of the FB madel predictions to the choice of the non-retarded Hamaker constant, by varying $Q$ by an order of magnitude higher and lower than the original mean estimate and recomputing $\mathrm{Clr}_{\mathrm{FB}}$ for a wide range of predator and prey size combinations. Similarly, the effects of grazer swimming speed was examined by recomputing $\mathrm{Cl}_{\mathrm{FB}}$ with $\mathrm{U}_{\mathrm{g}}=$ 50,400 and $800 \mu \mathrm{m} \mathrm{s}^{-1}$.

\section{RESULTS}

Fig. 2 shows the grazer and prey size dependencies of clearance rate estimates for the Force Balance and Geometric models with standard parameter values $\left(\mathrm{U}_{\mathrm{g}}\right.$ $=200 \mu \mathrm{m} \mathrm{s}^{-1}$ and $Q=3.7 \times 10^{-21} \mathrm{~J}$ ). Within the range $\left(0.03<\mathrm{R}_{\mathrm{p}} / \mathrm{R}_{\mathrm{g}}<0.3\right)$, values of $\mathrm{Clr}_{\mathrm{FB}}$ and $\mathrm{Clr}_{\mathrm{GEO}}$ vary from 0.13 to $1.8 \mathrm{nl} \mathrm{flag}{ }^{-1} \mathrm{~h}^{-1}$ and from 0.03 to $1.9 \mathrm{nl}$ flag $^{-1} \mathrm{~h}^{-1}$, respectively. $\mathrm{Clr}_{\mathrm{FB}}$ increases roughly linearly with grazer and with prey diameters. Conversely, ClrGeo increases quadratically with prey diameter and is independent of grazer diameter.

Fig. 3 compares the dependency of the specific clearance rate on grazer and prey size for the 2 models. $\mathrm{SpClr}_{\mathrm{FB}}$ and $\mathrm{SpClr}_{\mathrm{GEO}}$ vary from 0.09 to $7.6 \times 10^{4} \mathrm{~h}^{-1}$ and from 0.01 to $7.2 \times 10^{4} \mathrm{~h}^{-1}$, respectively. SpCli $\mathrm{GEO}$ exhibits a stronger size dependency for both grazer and prey size relative to $\mathrm{SpCl}_{\mathrm{FB}}$. The divergence of the 2 models caused by the different size dependencies is illustrated in Fig. 4 by the ratio $\mathrm{Clr}_{\mathrm{FB}} / \mathrm{Clr}_{\mathrm{GEO}}$. Within the range $0.03<\mathrm{Rp} / \mathrm{Rg}<0.3$, the ratio varies from about 1 to 10. Consequently, the Force-Balance model generally predicts higher clearance rates relative to the Geometric model with the greatest disparity for larger grazers utilizing relatively small prey. The predictions of the 2 models are similar for small grazers feeding on relatively large prey.

The dimensionless adhesion number, $N_{a d s}$ (Eq. 5), for stanclard model parameters $\left(\mathrm{U}_{\mathrm{g}}=200 \mu \mathrm{m} \mathrm{s} \mathrm{s}^{-1}\right.$ and $\mathrm{Q}=$ $\left.3.7 \times 10^{-21} \mathrm{~J}\right)$, is presented in Fig. 5. Within the range $0.03<R_{p} / R_{g}<0.3, N_{a d s}$ ranges from 0.03 to 150 . For $N_{\text {ads }}$ $>1$, the London-van der Waals force is large relative to the hydrodynamic interaction component and consequently, the Force Balance model predicts higher clearance rates relative to the Geometric model. The largest values of $\mathrm{N}_{\text {ads }}$ are associated with large grazer and relatively small prey and the smallest $N_{\text {ads }}$ for small grazers feeding on relatively large prey. The general trend in $N_{\text {ads }}$ closely follows that of the ratio $\mathrm{Clr}_{\mathrm{FB}} / \mathrm{Clr}_{\mathrm{GEO}}$ (Fig. 4).

For grazers of known size, the dependency of specific clearance rate on prey size is given by the expression $\mathrm{SpCl}_{\mathrm{FB}}=\mathrm{C}_{1} \mathrm{R}_{\mathrm{p}}{ }^{\mathrm{X}_{1}}$. Within the applicable size range, the exponent $X_{1}$ varies from 0.6 to 1.1 (Fig. 6 upper). Small grazers feeding on large prey show greater size-selection relative to large grazers feeding on small prey. All estimates of $X_{1}$ are well below the constant value of 2.0 predicted by the Geometric model.

For prey of a known size, the dependency of specific clearance rate on grazer size is given by the expression $\mathrm{SpClr}_{\mathrm{FB}}=\mathrm{C}_{2} \mathrm{R}_{\mathrm{g}} \mathrm{X}_{2}$. Again, within the size range $0.03<R_{p} / R_{g}<0.3$, the exponent $X_{2}$ varies from -2.5 to -2.3 indicating that specific clearance rate falls off with increasing grazer size (Fig. 6 lower). The ForceBalance model predicts a more gradual decrease in specific clearance rate with increases in grazer size than does the Geometric model which predicts a constant exponent $\mathrm{X}_{2}=-3.0$.

The combination of grazer and prey size effects on clearance rate is illustrated in Fig. 7. This figure shows that $\mathrm{SpClr}_{\mathrm{FE}}$ is much less sensitive to changes in $\mathrm{R}_{\mathrm{p}} / \mathrm{R}_{\mathrm{g}}$ relative to predictions for $\mathrm{SpClr}_{G E O}$. The linearity of the relationships is fortuitous in that the resulting regression equations allow one to make rough predictions of $\mathrm{Clr}_{\mathrm{FB}}$ without extensive numerical analysis. 
Fig. 2. Model results for clearance rate dependency on grazer and prey sizes. Upper: Force-Balance model; lower: Geometric model. Shaded area represents the practical combinations of prey and grazer radii discussed in the text (i.e. $0.03 \leq \mathrm{R}_{\mathrm{p}} / \mathrm{R}_{\mathrm{g}} \leq 0.3$ )

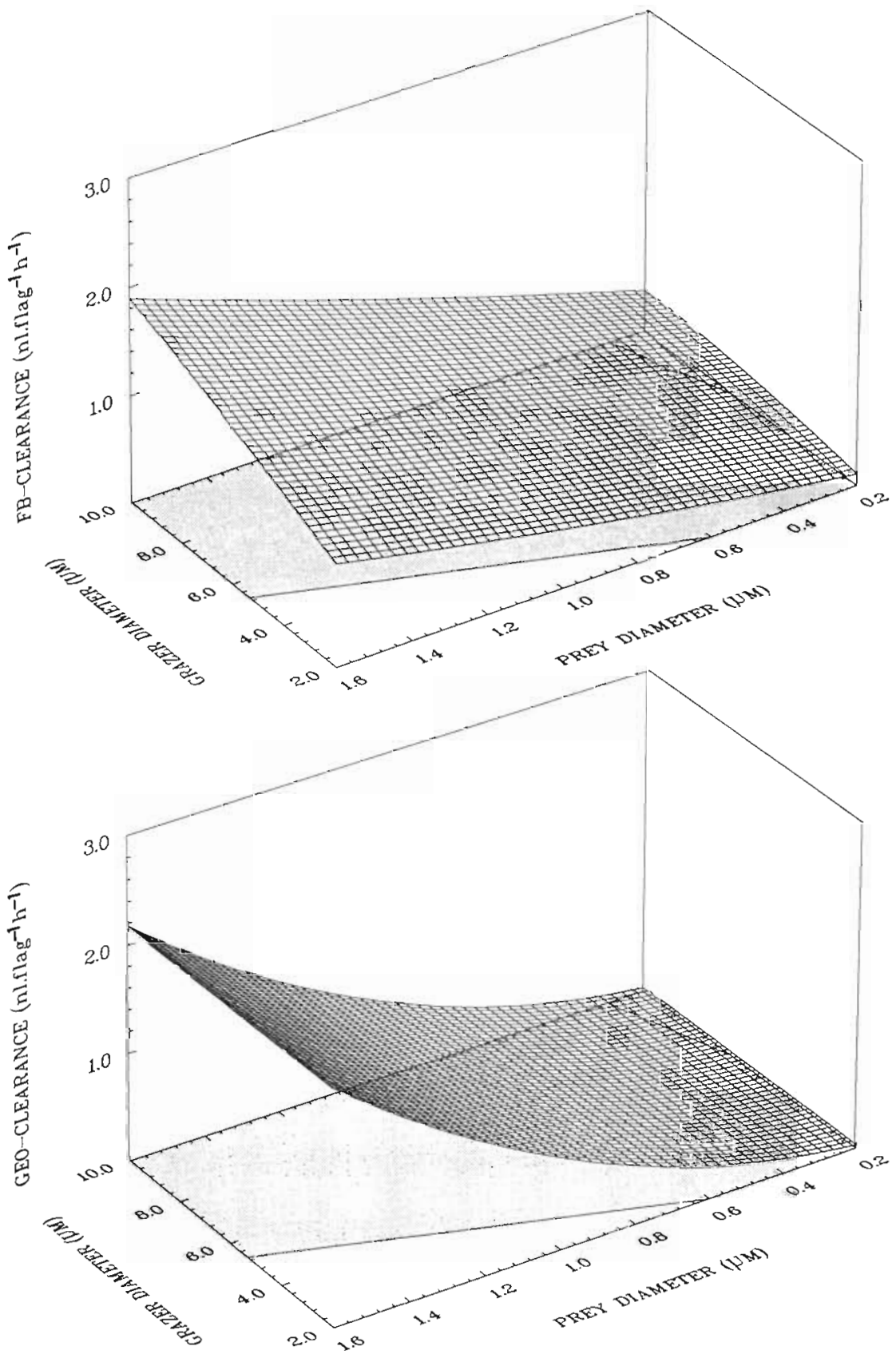

The sensitivity of model results to choice of $Q$ is presented in Fig. 8 (upper) as the ratios $\mathrm{Clr}_{\mathrm{FB}-20}$ ' $\mathrm{Clr}_{\mathrm{FB}-21}$ and $\mathrm{Clr}_{\mathrm{FB}-22} / \mathrm{Clr}_{\mathrm{FB}-21}$, where the numeric portion of the subscript represents the exponent a in the expression $Q=3.7 \times 10^{a}$. Results for grazer diameters of $4,6,8$, and $10 \mu \mathrm{m}$ are combined into a single scatter plot. This analysis indicates that order of magnitude changes in $Q$ produce only 2-fold changes in predictions of clearance rates. Moreover, this effect is fairly constant over a wide range of grazer and prey sizes.

The results of the sensitivity analysis for grazer swimming speed $\left(\mathrm{U}_{\mathrm{g}}\right)$ are given in Fig. 8 (lower) as the ratios $\mathrm{Clr}_{\mathrm{FB}-50} / \mathrm{Cl}_{\mathrm{FB}-200}, \mathrm{Clr}_{\mathrm{FB}-400} / \mathrm{Clr}_{\mathrm{FB}-200}$ and $\mathrm{Clr}_{\mathrm{FB}-800} / \mathrm{Clr}_{\mathrm{FB}-200}$, where the numeric portion of the subscript indicates the velocity $U_{g}\left(\mu \mathrm{m} \mathrm{s}^{-1}\right)$ used in the calculation of clearance rates. As above, the results for grazer diameters of $2,4,6,8$, and $10 \mu \mathrm{m}$ are combined in a single scatter plot. The sensitivity of clearance rate predictions to $U_{g}$ are fairly constant over a wide range of grazer and prey sizes. Increases in $U_{g}$ of 2 - and 4 -fold produce roughly 1.5 and 2.5 -fold increases in the estimate of $\mathrm{Clr}_{\mathrm{FB}}$, respectively. 


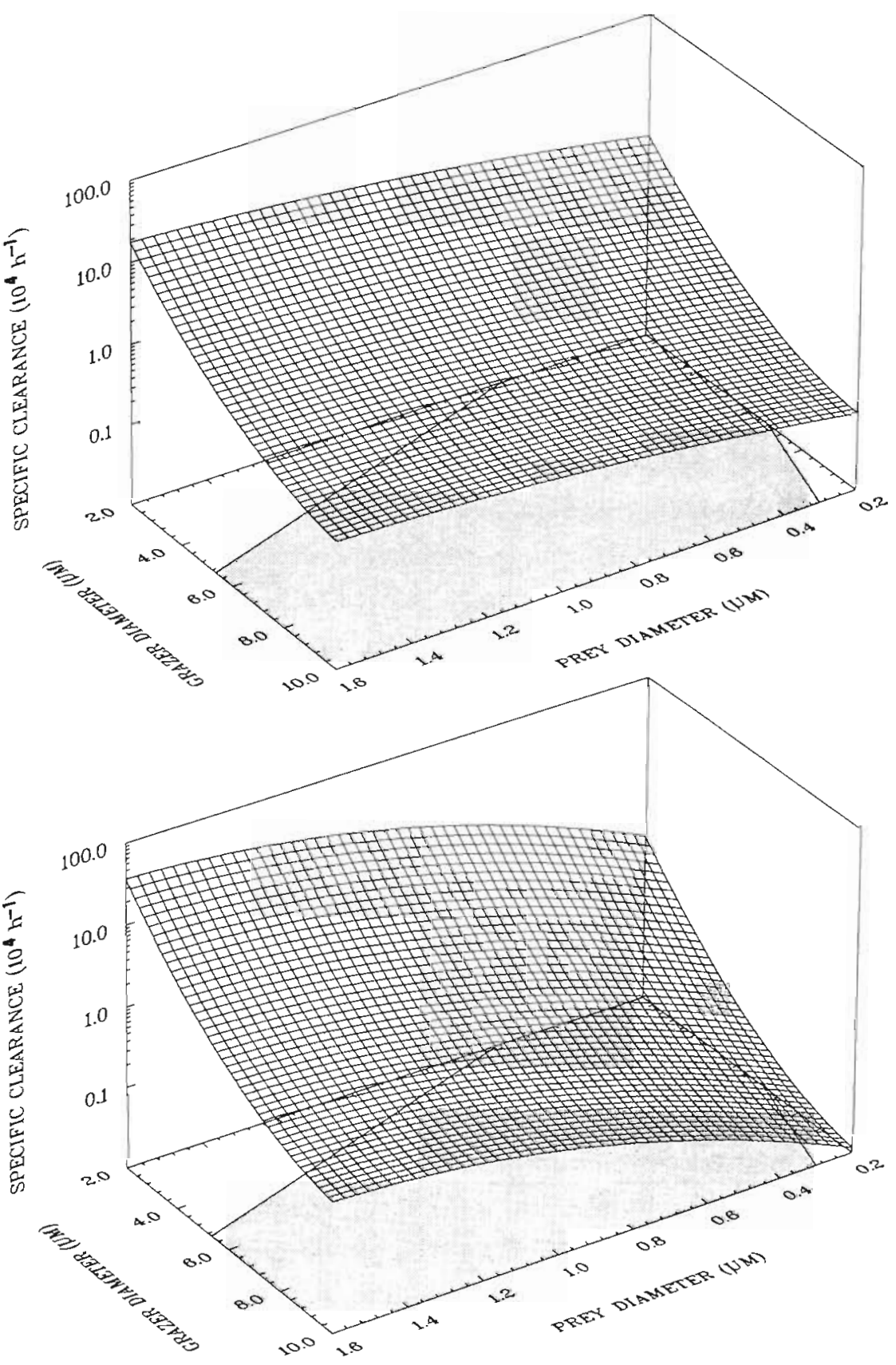

Fig. 3. Model results for the specific clearance rate dependency on grazer and prey sizes. Upper Force-Balance model lower: Geometric model. Note that the grazer axis has been reversed relative to Fig. 2 to give better perspective of the surface. Shaded area same as Fig. 2

\section{DISCUSSION AND CONCLUSIONS}

The present paper describes a general scheme for modeling direct-interception feeding by zooflagellates which is derived from basic principles of fluid dynamics and physical chemistry. We show that for low Re motion, the balance between fluid drag and externally applied forces on prey determines the nature of the capture process. The utility of this 'Force-Balance' modelling approach is in reducing the complex capture process to the sum of individual force components. By systematically studying these individual components under controlled conditions, it may be possible to construct more accurate physical models of the zooflagellate grazing process.

Within the context of this approach, we present a model which represents a reasonable first approxima. tion of the actual capture process. According to this model, the process of direct-interception feeding by zooflagellates can be viewed as follows with prey beginning their approach to the zooflagellate along fluid streamlines. At a distance of ca $750 \mathrm{~nm}(2.5 \mathrm{R})$ 
Fig. 4. Comparison of Force-Balance (FB) and Geometric (GEO) model estimates of clearance rates. Ratio of clearance rate estimates $\left(\mathrm{Cl}_{\mathrm{FB}} / \mathrm{Clr}_{\mathrm{GEO}}\right)$ for the 2 models is plotted as a function of grazer and prey diameter Shaded area same as Fig. 2
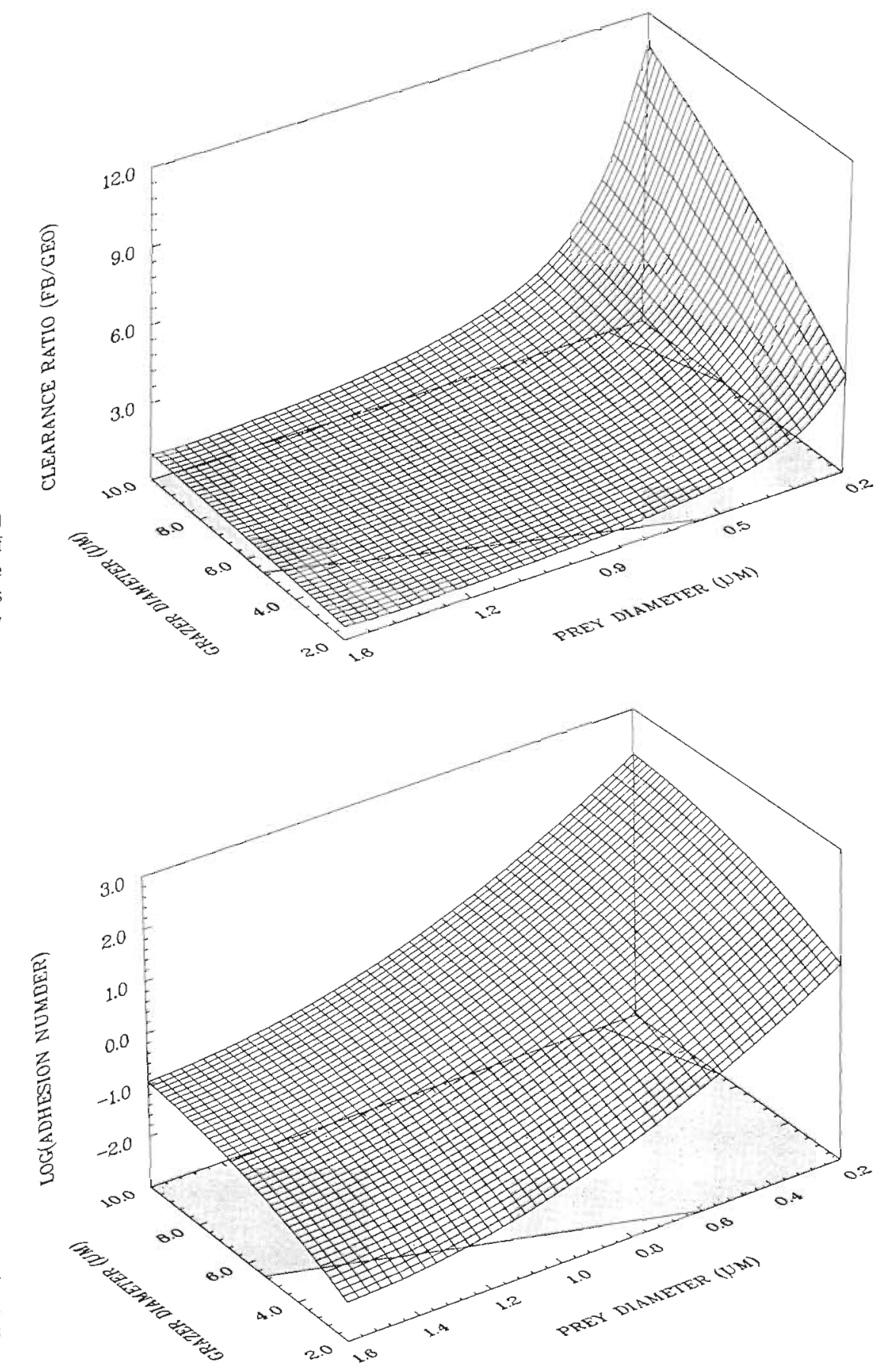

Fig. 5. Dependency of adhesion number $\left(\mathrm{N}_{\mathrm{ads}}\right)=\mathrm{Q} \mathrm{R}_{\mathrm{g}}{ }^{2} /\left(9 \pi \mu \mathrm{U}_{\mathrm{g}} \mathrm{R}_{\mathrm{p}}{ }^{4}\right)$ on prey and grazer diameter Shaded area same as Fig. 2 from the grazer's surface the prey begins to 'feel' the repulsive force due to the hydrodynamic interaction with the grazer. This force causes the prey to move up off its original streamline. As the prey approaches to within about $200 \mathrm{~nm}$ of the grazer's surface, it begins to feel the rapidly increasing pull of the attractive London-van der Waals force. If the London-van der Waals force is weak relative to the repulsive hydrodynamic interaction, the prey will continue to be pushed away from the grazer surface relative to its original streamline and escape. If the London-van der Waals force is strong relative to the repulsive hydrodynamic interaction, the prey will be pulled below the streamline that it was initially moving along and will spiral in toward the grazer's surface until it encounters a primary minimum somewhere between 3 and $5 \mathrm{~nm}$. We assume that if the prey is recognized as 'good' via specific receptor molecules, membrane rearrangement takes place with 


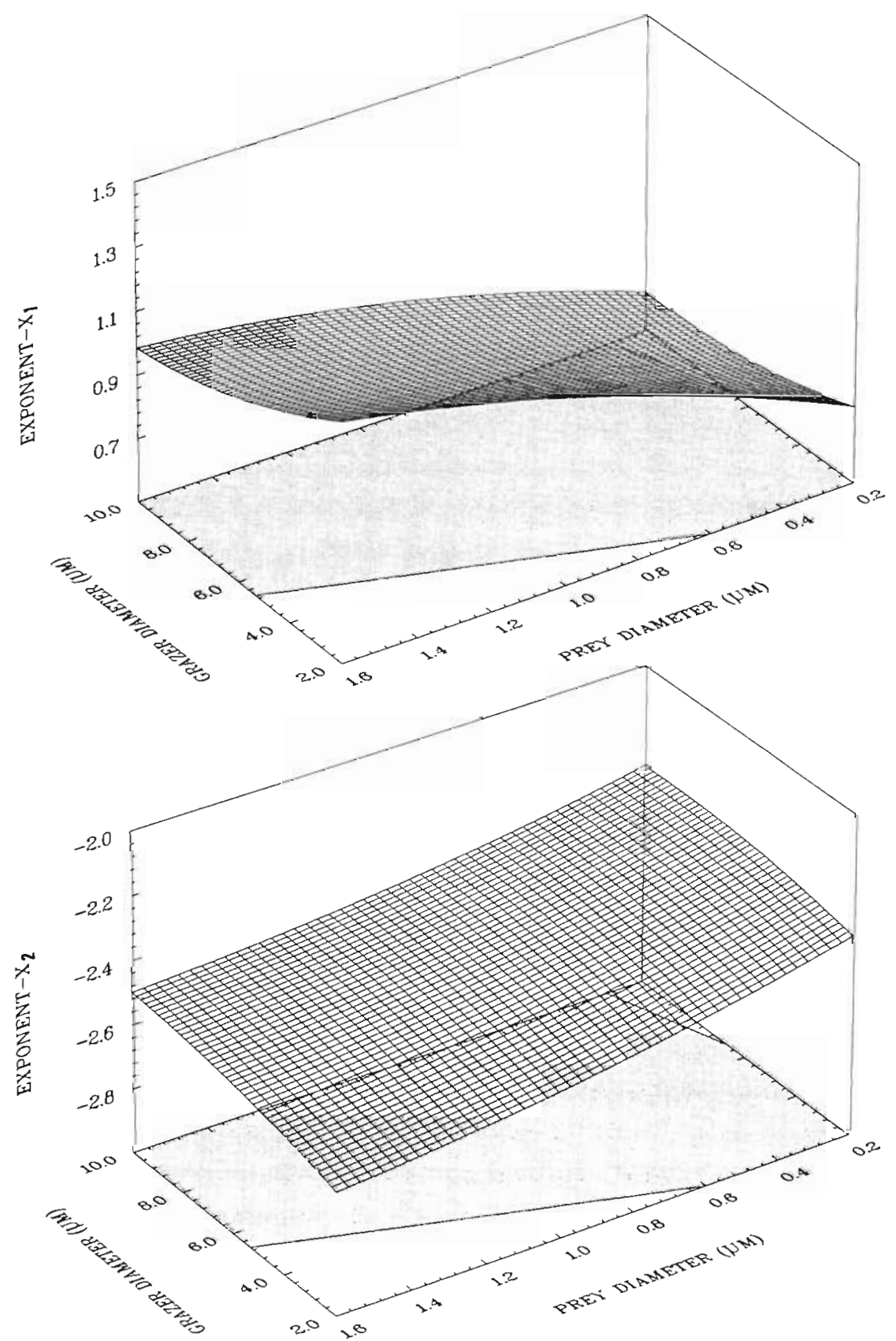

Fig. 6. Strength of dependency of prey and grazer size on specific clearance rate. Upper: Exponent $X_{1}$ of the expression $\mathrm{SpClr}=\mathrm{c}_{1} R_{\mathrm{p}} \mathrm{X}_{1}$ plotted as a function of prey-grazer size. Lower: Exponent $\mathrm{X}_{2}$ of the expression $\mathrm{SpClr}=\mathrm{C}_{2} \mathrm{R}_{\mathrm{g}}{ }^{\mathrm{X}_{3}}$ plotted as a function of prey-grazer size. Results of the Geometric model (not presented here) yield constant values of 2.0 and -3.0 respectively for $\mathrm{X}_{1}$ and $\mathrm{X}_{2}$. Shaded area same as Fig. 2

subsequent engulfment. We assume this engulfment process is rapid relative to the time required between subsequent prey contacts (i.e. food limited).

Clearance rate estimates using this model are up to a factor of 10 greater than those from the Geometric model described by Fenchel (1982a, 1984). The Geometric model ignores hydrodynamic resistance due to the presence of a grazer surface as well as all surface-forces so that the prey is assumed to follow fluid streamlines to contact. According to the model we have presented, the attractive London-van der Waals force generally dominates the repulsive component of the fluid drag resulting in higher clearance rate predictions, particularly for relatively large zooflagellates feeding on small prey. Because adhesion number (Eq. 5; Fig. 5) is a rough indicator of the relative strength of these 2 forces, it is an important indicator of the deviation of the 2 models.

The current model predicts a moderate size dependency to clearance rate in which Clr increases roughly in proportion to $R_{p}^{0.8}$. This contrasts sharply with the proportionality $\mathrm{R}_{\mathrm{p}}{ }^{2}$ predicted by the Geometric model. The explanation for this discrepancy is that the hydrodynamic resistance force declines more rapidly with 

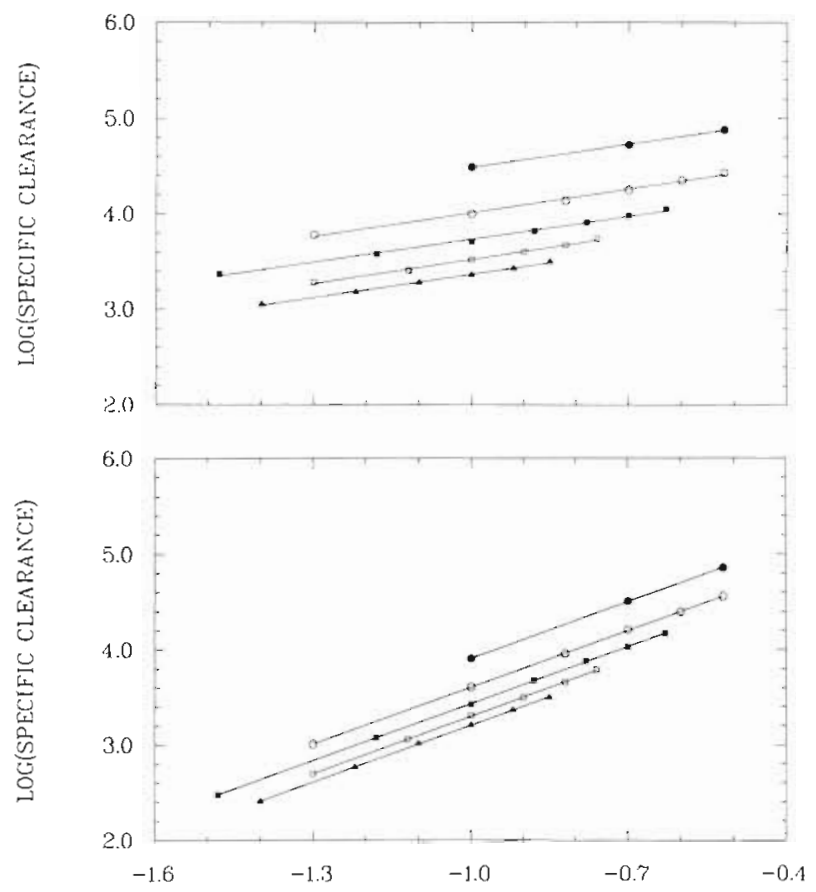

$\operatorname{LOG}(\mathrm{Rp} / \mathrm{Rg})$

Fig. 7. Combined effects of prey and grazer sizes on specific clearance rate. Results of the Force-Balance model (upper), and Geometric model (lower) for grazer diameters: $(\bullet) 2.0 \mu \mathrm{m}$, (0) $4.0 \mu \mathrm{m}$, (-) $6.0 \mu \mathrm{m}$, (ㅁ) $8.0 \mu \mathrm{m}$, and (\$) $10.0 \mu \mathrm{m}$. Corresponding slopes and intercepts for the lines of the Force-Balance model are: $(\bullet) \mathrm{S}=0.82, \mathrm{I}=5.30 ;(0) \mathrm{S}=0.84, \mathrm{I}=4.85$; (-) $\mathrm{S}=$ $0.83, \mathrm{I}=4.56$; (ㄷ) $\mathrm{S}=0.85, \mathrm{I}=4.38$; and $(\lambda) \mathrm{S}=0.81, \mathrm{I}=4.18$

decreasing prey diameter than the attractive Londonvan der Waals force. Therefore, the decrease in clearance that would be expected from geometric considerations alone is offset by the relative increase in the London-van der Waals force over hydrodynamic resistance.

Predator-prey size relationships are the foundation of our present understanding of marine food-web structure. Consequently, major discrepancies in predicted size relationships have important ecological implications. For instance, the $\mathrm{R}_{\mathrm{p}}{ }^{2}$ relationship for clearance rate as a function of prey size predicted by the Geometric model indicates that bacteria of $0.8 \mu \mathrm{m}$ diameter should be grazed upon at rates 16 times higher than those $0.2 \mu \mathrm{m}$ diameter bacteria. This implies a very strong size-refuge from grazing for the smallest bacteria and argues for high compensating growth rates of larger bacteria. In contrast, the Force-Balance predictions suggest that there should only be a factor of 3 difference in grazing impacts on bacteria in the size range 0.2 to $0.8 \mu \mathrm{m}$. The Geometric model also predicts that clearance rates on bacteria of a given size are independent of grazer size - i.e. specific clearance rate
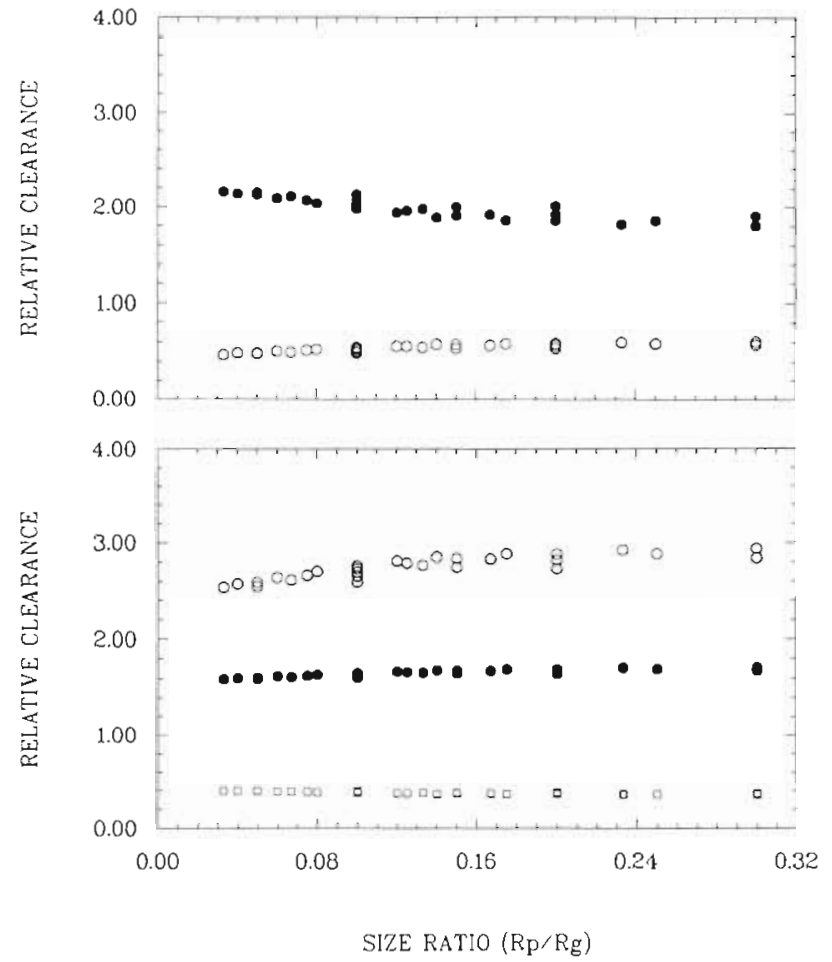

Fig. 8. Sensitivity analysis of Force-Balance model using: (upper) Hamaker constant $Q=\left(\bullet 3.7 \times 10^{-20}\right.$ (0) $3.7 \times 10^{-22}$; (lower) grazer swimming speed $U_{g}=(0) 800 \mu \mathrm{m} \mathrm{s}^{-1},(\bullet) 400$ $\mu \mathrm{m} \mathrm{s} \mathrm{s}^{-1}$, and (口) $50 \mu \mathrm{m} \mathrm{s}^{-1}$ Results expressed as the ratio of clearance rate of perturbed model to predictions using standard model parameters $\left(\mathrm{U}_{\mathrm{g}}=200 \mu \mathrm{m} \mathrm{s}^{-1}, \mathrm{Q}=3.7 \times 10^{-21}\right)$

declines as $\mathrm{R}_{\mathrm{g}}{ }^{-3}$. The Force-Balance model, on the other hand, predicts that clearance rates for a given prey size will increase with grazer size. Consequently, relatively large flagellates (e.g. $10 \mu \mathrm{m}$ ) may be able to feed on small bacteria at rates up to 10 times more efficiently than predicted by the Geometric model.

Experimentally-determined estimates of zooflagellate grazing rates on picoplankton-sized particles are listed in Table 2 . The observed clearance rates $\left(\mathrm{Cl}_{\mathrm{OB}}\right)$ fall largely in the range 0.1 to $10.0 \mathrm{nl} \mathrm{flag}^{-1} \mathrm{~h}^{-1}$. Corresponding specific clearance rates (SpClroB) are in the range 0.1 to $11.0 \times 10^{4} \mathrm{~h}^{-1}$. The predicted rate estimates for comparably sized zooflagellates and prey range from 0.4 to $1.0 \mathrm{nl} \mathrm{flag}{ }^{-1} \mathrm{~h}^{-1}$ and from 0.7 to $3.0 \times 10^{4} \mathrm{~h}^{-1}$ for $\mathrm{Clr}_{\mathrm{FB}}$ and $\mathrm{SpClr}_{\mathrm{FB}}$, respectively, when the ForceBalance model is run with standard parameters $\left(\mathrm{U}_{\mathrm{g}}=\right.$ $200 \mu \mathrm{m} \mathrm{s}^{-1}, \mathrm{Q}=3.7 \times 10^{-21} \mathrm{~J}$ ). Where direct comparisons can be made (Table 2 ), model results are frequently comparable, and generally within a factor of 2 , of observed rates. However, the highest experimental estimates (e.g. Fenchel 1982a) are as much as an order of magnitude greater than the theoretical predictions. Moreover, it is a matter of concern that the best agree- 


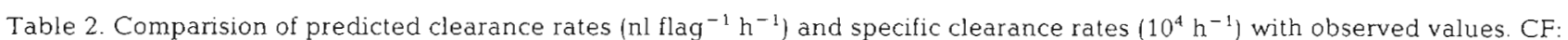
cultured flagellate; NFP: natural flagellate population; CB: cultured bacteria; FLB: fluorescently labeled bacteria; LB: latex beads; PP: paint particles

\begin{tabular}{|c|c|c|c|c|c|c|}
\hline \multirow{2}{*}{$\begin{array}{l}\text { Grazer type } \\
\text { diam. (um) }\end{array}$} & \multirow{2}{*}{$\begin{array}{l}\text { Prey type } \\
\text { diam. }(\mu \mathrm{m})\end{array}$} & \multicolumn{2}{|c|}{ Clearance rate } & \multicolumn{2}{|c|}{ Specific clearance rate } & \multirow[t]{2}{*}{ Source } \\
\hline & & Predicted & Observed & Predicted & Observed & \\
\hline $4.4 \mathrm{CF}$ & $1.2^{a} \mathrm{CB}$ & 0.95 & 10.0 & 2.0 & 11.0 & Fenchel (1982b) \\
\hline $3.8 \mathrm{CF}$ & $1.2 \mathrm{CB}$ & 0.88 & $0.45,0.65,0.95$ & 2.8 & $1.5,2.2,3.2$ & Sherr et al. (1983) \\
\hline $3.8 \mathrm{CF}$ & $0.8 \mathrm{CB}$ & 0.58 & 0.35 & 1.8 & 1.2 & Sherr et al. (1983) \\
\hline $4.0 \mathrm{CF}$ & $0.67 \mathrm{PP}$ & 0.53 & 0.6 & 1.6 & 1.8 & McManus \& Fuhrman (1986) \\
\hline $5.2 \mathrm{CF}$ & $0.53 \mathrm{LB}$ & 0.48 & 0.1 & 0.55 & 0.14 & Sieracki et al. (1987) \\
\hline 5-15 NFP & $0.53 \mathrm{LB}$ & 0.69 & 0.04 & 0.13 & 0.008 & Sieracki et al. (1987) \\
\hline NFP & $0.6 \mathrm{FLB}$ & & 3.2 & & no data & Sherr et al. (1987) \\
\hline $2.8-4.0 \mathrm{NFP}$ & $0.67 \mathrm{PP}$ & 0.49 & $1.2(\operatorname{avg}$. of 17$)$ & 3.0 & 6.1 (avg. of 17 ) & McManus \& Fuhrman (1988) \\
\hline$C F$ & $0.7^{\circ} \mathrm{CB}$ & & 2.8 (avg. of 4$)$ & & no data & Nygaard et al. (1988) \\
\hline $\mathrm{CF}$ & $0.57 \mathrm{LB}$ & & 0.8 (avg. of 4$)$ & & no data & Nygaard et al. (1988) \\
\hline $3.0,3.3 \mathrm{NFP}$ & $0.57 \mathrm{LB}$ & 0.41 & $7.0,0.4$ & 1.9 & $50,2.2$ & Nygaard et al. (1988) \\
\hline $4.2,4.0$ NFP & $0.57 \mathrm{LB}$ & 0.46 & $0.75,1.0$ & 1.4 & 1.9 .3 .0 & Nygaard et al. (1988) \\
\hline $4.4,2.7,4.6 \mathrm{NFP}$ & $0.57 \mathrm{LB}$ & 0.44 & $6.0,1.0,5.7$ & 1.6 & $13,9.1,11$ & Nygaard et al. (1988) \\
\hline
\end{tabular}

ment between experimental results and theory is obtained for experiments conducted with inert particles (latex beads or paint particles) which may be discriminated against by grazers relative to bacterial prey (Sherr et al. 1987). Given these concerns, the narrow sizerange of zooflagellates tested, the high variability in experimental results, and the general lack of measurement of important model parameters (e.g. swimming speeds), we clearly cannot draw definitive conclusions from the preceding comparison of observed and predicted rates. Nonetheless, in the following discussion, we assume that the present model somewhat underpredicts the true grazing potential of zooflagellates and offer several hypotheses which might explain this.

Speculation on the effects of neglecting hydrophobic and steric forces will not be presented here because they would not produce hypotheses that are testable at this time for reasons given in the theoretical section. Clearance rate predictions in the present model are entirely defined by 4 input parameters - the sizes of the zooflagellate grazer and prey particles, the swimming velocity of the zooflagellates, and the non-retarded Hamaker constant $Q$. Since size would seem to be the most easily measured parameter, one is tempted to accept it at face value. This assumption, however, is not strictly valid for the preceding comparison of predicted versus empirical results since the model predictions are based on the sizes of living zooflagellates while the experimental literature generally reports the sizes of preserved specimens. Børsheim \& Bratbak (1987) observed that $55 \%$ of the volume of a bacterivorous Monas species was lost in preservation. If the sizes of the zooflagellates in Table 1 were corrected for a similar magnitude of related shrinkage (i.e. about $30 \%$ increase in radius), predicted rates would be enhanced on average by about 16 and $18 \%$, respectively, relative to experimentally-determined clearance and specific clearance rates.

Our use of a constant swimming velocity $\left(\mathrm{U}_{\mathrm{g}}=\right.$ $200 \mu \mathrm{m} \mathrm{s}^{-1}$ ) for all zooflagellates was based on empirical results for 15 species spanning nearly 2 orders of magnitude in size (Fenchel 1987). However, within that data set, swimming speed estimates for the 4 species with $\mathrm{R}_{\mathrm{g}}<5 \mu \mathrm{m}(10 \mu \mathrm{m}$ diam.) ranged from 90 to $720 \mu \mathrm{m}$ $\mathrm{s}^{-1}$. From our sensitivity analysis (Fig. 7 lower), increasing $U_{\mathrm{g}}$ to $800 \mu \mathrm{m} \mathrm{s}^{-1}$ ( 4 -fold increase in $U_{\mathrm{g}}$ ) produces a 2.5-fold increase in $\mathrm{Clr}_{\mathrm{FB}}$. The less than proportional increase in $\mathrm{Clr}_{F B}$ with increasing $U_{\mathrm{g}}$ is due to a concomitant decrease in capture efficiency when the repulsive hydrodynamic interaction component of $F^{\prime}$ drag increases at higher $U_{g}$.

The value of $3.7 \times 10^{-21} \mathrm{~J}$ for the Hamaker constant $Q$ is the mean of empirically derived values from a number of different approaches ranging from 0.9 to $6.4 \times 10^{-21} \mathrm{~J}$. From the theoretical analysis of $\mathrm{Nir}$ (1976), the addition of a glycocalyx layer over the cell membrane would yield a $Q=6 \times 10^{-21} \mathrm{~J}$ which is the upper limit for simple lipid bilayers. Our model sensitivity analysis (Fig. 7 upper) indicates that a 10 -fold increase in $\mathrm{Q}$ produces only a 2-fold increase in $\mathrm{Cl}_{\mathrm{FB}}$. Therefore, we conclude that a reasonable upper estimate of $Q=6 \times 10^{-21} \mathrm{~J}$ (i.e. $<2$-fold increase in the mean value used in this model) would only modestly increase our predicted estimates of $\mathrm{Clr}_{\mathrm{FB}}$. However, if we use both high-end estimates of $\mathrm{U}_{g}$ and $\mathrm{Q}$ in the model, the predictions for $\mathrm{Clr}_{\mathrm{FB}}$ and $\mathrm{SpClr}_{\mathrm{FB}}(1.0$ to $3.0 \mathrm{nl} \mathrm{flag} \mathrm{fl}^{-1} \mathrm{~h}^{-1}$ and 2.4 to $8.7 \times 10^{4} \mathrm{~h}^{-1}$, respectively) are well within the high range of empirical results. 
In conclusion, any realistic model of direct-interception feeding of zooflagellate grazers on picoplankton prey must accurately account for the relevant physical and chemical forces acting on such tiny organisms in a seawater medium. The complex nature of these forces was made apparent in the theoretical section. Given the many simplifying assumptions in the present model, the fact that it provides rate predictions of the same order as empirical results is quite encouraging. While future work will elaborate on specific force components of this model to improve its predictive capability, it is also important that hypothesis testing go handin-hand with theoretical development. In this context, the model's predictions with regard to the size-dependency of clearance rates appear to be the most approachable avenue at this time since the predicted relationships are substantially different from (i.e. statistically amenable to testing) the results of the previous model (Fenchel 1982a, 1984) and because these 'relative-rate' predictions are likely to be less sensitive to variations in model parameters than predictions of absolute rates.

Acknowledgements. The authors thank the anonymous reviewer whose many comments contributed significantly to the quality of the final version of this paper. This research was supported by the National Science Foundation and the Office of Naval Research via Grants OCE-8614401 and OCE8841886

\section{LITERATURE CITED}

Adamczyk, Z., Dabros, J., Czarnecki, J., van de Ven, T G. M. (1983). Particle transfer to solid surfaces. Adv. Colloid Interface Sci. 19: 183-252

Azam, F., Fenchel T., Field, J. G., Gray, J. S., Meyer-Reil, L.-A., Thingstad, F. (1983). The ecological role of watercolumn microbes in the sea. Mar. Ecol. Prog. Ser. 10 $257-263$

Bell, G. I. (1988). Models of cell adhesion involving specific binding. In: Bongrand, P. (ed.) Physical basis of cell-cell adhesion. CRC Press, Boca Raton, p. 227-258

Bersheim, K. Y., Bratbak, G. (1987). Cell volume to cell carbon conversion factors for a bacterivorous Monas sp. enriched from seawater. Mar Ecol. Prog. Ser 36: 171-175

Brenner, $H$. (1961). The slow motion of a sphere through a viscous fluid towards a plane surface. Chem. Engn. Sci. 16 $242-251$

Cowley, A. C., Fuller, N. L., Rand, R. P., Parsegian, V A. (1978). Measurement of repulsive forces between charged phospholipids. Biochemistry 17.3163-3168

Derjaguin, B. V., Landau, L. (1941). Theory of the stability of strongly charged sols and of the adhesion of strongly charged particles in solutions of electrolytes. Acta Physiochim. URSS 14 : 633-662

Ducklow, H. W., Purdie, D. A., Williams, P. J. LeB., Davies J. M. (1986). Bacterioplankton: a sink for carbon in a coastal marine plankton community. Science 232: 865-867

Evans, D. F., Ninham, B. W. (1986). Molecular forces in the self-organization of amphiphiles. J. phys. Chem. 90: $226-234$
Fenchel, T (1982a). Ecology of heterotrophic microflagellates I. Some important forms and their functional morphology. Mar. Ecol. Prog. Ser 8: 211-223

Fenchel, T (1982b). Ecology of heterotrophic microflagellates II. Bioenergetics and growth. Mar Ecol. Prog. Ser 8 225-231

Fenchel, T (1984). Suspended marine bacteria as a food source. In: Fasham, M. J. (ed.) Flows of energy and materials in marine ecosystems. Plenum Press. New York

Fenchel, T (1987). Ecology of protozoa: the biology of freeliving phagotrophic protists. Springer-Verlag, New York

Fitzpatrick, J. A. (1972). Ph.D. thesis, Harvard Univ., Cambridge

Gerald, C. F. (1980). Applied numerical analysis, 2nd edn. Addision-Wesley, Reading

Gerritsen, J., Bradley, S. W. (1987). Electrophoretic mobility of natural particles and cultures organisms in freshwaters. Limnol. Oceanogr. 32: 1049-1058

Goldman, A. J., Cox, R. G., Brenner, H. (1967a). Slow viscous motion of a sphere parallel to a plane wall - I. Motion through a quiescent fluid. Chem. Engn. Sci. 22: $637-651$

Goldman, A. J., Cox, R. G., Brenner, H. (1967b). Slow viscous motion of a sphere parallel to a plane wall - II. Coulette flow. Chem. Engn. Sci. 22: 653-668

Goren, S. L. (1970). The normal force exerted by creeping flow on a small sphere touching a plane. J. Fluid Mech. 41 $619-640$

Goren, S. L., O'Neill, M. E. (1971). On the hydrodynamic resistance to a particle of dilute suspension when in the neighborhood of a large obstacle. Chem. Engn. Sci. 26: $325-338$

Hamaker, H. C. (1937). The London-van der Waals attraction between spherical particles. Physica (The Hague) 4 1058-1072

Happel, J. (1959). Viscous flow relative to arrays of cylinders. A. I. Ch. E. J. 5: 197-201

Hiemenz, P.C. (1986). Principles of colloid and surface chemistry, 2nd edn. Marcel Dekker Inc., New York

Hobbie, J. F., Williams, P. J. LeB. (ed.) (1984). Heterotrophic activity in the sea. Plenum Press, New York

Hogg, R., Healy, T W., Fuerstenau, D. W (1966). Mutual coagulation of colloidal dispersions. Trans. Faraday Soc. 66: $1638-1651$

Horn, R. G. (1984). Direct measurement of the force between two lipid bilayers and observation of their fusion. Biochim Biophys. Acta 778: 224-228

Hunter, F. A. (1980). Microelectrophoretic properties of natural surface-active organic matter in coastal seawater. Limnnol. Oceanogr 25: 807-822

Israelachvili, J. N. (1985). Intermolecular and surface forces with applications to colloidal and biological systems Academic Press, New York

Israelachvili, J. N. (1987). Hydrophobic interactions. In: Safran, S. A., Clark, N. A. (eds.) Physics of complex and supermolecular fluids. John Wiley and Sons, New York, p. 101-113

Israelachvili, J. N., Adams, G. E. (1978). Measurement of forces between two surfaces in aqueous electrolyte solutions in the range 0-100 nm. J. Chem. Soc. Faraday Trans. I. $74: 975-1001$

Israelachvili, J. N., McGuiggan, P. M. (1988). Forces between surfaces in liquids. Science 241: 795-800

Israelachvili, J. N. Pashley, R. (1982). The hydrophobic interaction is long range, decaying exponentially with distance. Nature, Lond. 300: 341-342 
Israelachvili, J., N., Tabor, D. (1973). Van der Waals forces: theory and experiment. Prog. Surf. Membr. Sci. 7: 1-55

LaBarbera, M. (1984). Feeding currents and particle capture mechanisms in suspension feeding animals. Am. Zool. 24: $71-84$

Lazier, J. R. N., Mann, K. H. (1989). Turbulence and the diffusive layers around small organisms. Deep Sea Res. 36 : $1721-1733$

Lehninger, A. L. (1982). Principles of biochemistry. Worth, New York

LeNeveu, D. M., Rand, R. P., Gingell, D., Parsegian, V A. (1976). Apparent modification of forces between lecithin bilayers. Science 191: 399-400

Lifshitz, E. M. (1956). The theory of molecular attractive forces between solids. Sov. Phys. JETP (Engl. Transl.) 2: 73-83

Lis, L. J, McAlister, M., Fuller, N., Rand, R. P., Parsegian, V. A. (1982). Interactions between neutral phospholipid bilayer membranes. Biophys. J. 37: 657-666

Mahatny, J., Ninham, B. W. (1976). Dispersion forces. Academic Press, New York

Marra, J. (1986). Direct measurement of interaction between phosphatidylglycerol bilayers in aqueous electrolyte solutions. Biophys. J. 50: 815-825

Marra, J., Israelachvili, J. (1985). Direct measurements of forces between phosphatidylcholine and phosphatidylethanolamine bilayers in aqueous electrolyte solutions. Biochemistry 24: 4608-4618

McGuiggan, P. M., Pashley, R. M. (1988). Molecular layering in thin aqueous films. J. phys. Chem. 92: 1235-1239

McManus, G. B., Fuhrman, J. A. (1986). Bacterivory in seawater studied with the use of inert fluorescent particles Limnol. Oceanogr. 31. 420-426

McManus, G. B., Fuhrman, J. A. (1988). Clearance of bacteriasized particles by natural populations of nanoplankton in Chesapeake Bay outflow plume. Mar. Ecol. Prog. Ser 42: 199-206

Nir, S. (1976). Van der Waals interactions between surfaces of biological interest. Prog. Surf. Sci. 8: 1-58

Nygaard, K., Børsheim, K. Y., Thingstad, T F. (1988). Grazing rates on bacteria by marine heterotrophic microflagellates compared to uptake rates of bacterial-sized monodispersed fluorescent latex beads. Mar. Ecol. Prog. Ser. 44: 159-165

This article was submitted to the editor
Parsegian, V. A., Fuller, N., Rand, R. P. (1979). Measured work of deformation and repulsion of lecithin bilayers. Proc. natn. Acad. Sci. USA 76: 2750-2754.

Pashley, R. M., McGuiggan, P. M., Ninham, B. W., Evans, D. F. (1985). Attractive forces between uncharged hydrophobic surfaces: direct measurements in aqueous solution. Science 229: 1088-1089

Purcell, E. M. (1978). The effect of fluid motion on the absorption of molecules by suspended particles. J. Fluid Mech. 84: $551-559$

Rand, R. P. (1981). Interacting phospholipid bilayers: measured forces and induced structural changes. Ann. Rev. Biophys. Bioeng. 10: 277-314

Rogers, H. J. (1983). Bacterial cell structure. Van Nostrand Reinhold Co., Wokingham

Sherr, B. F., Sherr, E. B., Berman, T. (1983). Grazing, growth, and ammonium excretion rates of a heterotrophic microflagellate fed with four species of bacteria. Appl. environ. Microbiol 45: 1196-1201

Sherr, B. F., Sherr, E. B., Fallon, R. D. (1987). Use of monodispersed, fluorescently labeled bacteria to estimate in situ protozoan bacterivory. Appl. environ. Microbiol. 53: 958-965

Sherr, E. B., Sherr, B. F. (1987). High rates of consumption of bacteria by pelagic ciliates. Nature, Lond. 325: $710-711$

Silver, B. L. (1985). The physical chemistry of membranes. Solomon Press, New York

Sieracki, M. E., Haas, L. W., Caron, D. A., Lessard, E. J. (1987) Effect of fixation on particle retention by microflagellates: underestimation of grazing rates. Mar. Ecol. Prog. Ser. 38: $251-258$

Spielman, L. A., Fitzpatrick, J. A. (1973). Theory for particle collection under London and gravity forces. J. Colloid Interface Sci. 42: 607-623

Spielman, L. A., Goren, S. L. (1970). Capture of small particles by London forces from low-speed flows. Environ. Sci. Tech. 4: $135-140$

Spielman, L. A. (1977). Particle capture from low-speed laminar flows. Ann. Rev. Fluid Mech. 9: 297-313

Verwey, E. J. W., Overbeek, J. Th. G. (1948). Theory of stability of lyophobic colloids. Elsevier, Amsterdam

Manuscript first received: October 31, 1989

Revised version accepted: April 23, 1990 